\title{
What Did the Credit Market Expect of Argentina Default? Evidence from Default Swap Data
}

\author{
Frank X. Zhang*
}

April 16, 2003

* Federal Reserve Board, Division of Research and Statistics, Mail Stop 91, Washington DC 20551. I can be reached at Tel: 202-452-3760, Fax: 202-728-5887, Email: xzhang@frb.gov. I thank Allen Zhang and Hao Zhou for many discussions, and Alain Chaboud for providing part of data. I also thank Gurdip Bakshi, Dilip Madan, Mike Gibson, Michael Gordy, Matt Pritsker, Pat White and seminar participants at the Federal Reserve Board for helpful suggestions. Matthew Chesnes and Adam Sanjurjo provided excellent research assistance. The views expressed herein are the authors own and do not necessarily reflect those of the Federal Reserve Board or its staff. 


\begin{abstract}
This article explores the expectations of the credit market by developing a parsimonious default swap model, which is versatile enough to disentangle default probability from the expected recovery rate, accommodate counterparty default risk, and allow flexible correlation between state variables. We implements the model to a unique sample of default swaps on Argentine sovereign debt, and found that the risk-neutral default probability was always higher than its physical counterpart, and the wedge between the two was affected by changes in the business cycle, the U.S. and Argentine credit conditions, and the overall strength of the Argentine economy. We also found that major rating agencies had assigned over-generous ratings to the Argentine debt, and they lagged the market in downgrading the debt.
\end{abstract}




\section{Introduction}

In the last several years, the credit derivatives market has experienced explosive growth. A recent survey by Risk magazine shows that the total notional amount of outstanding credit derivatives contracts of the participants in the survey is $\$ 2,306$ billion, which is more than fifty percent higher than in Risk's previous annual survey and is forty times the size in late 1997. ${ }^{1}$ A conspicuous feature of the market is the increasing dominance of the plain-vanilla default swap contracts, especially the medium maturity contracts. The total notional outstanding for vanilla default swaps amounts to $\$ 1,671$ billion, accounting for more than seventy percent of the credit derivatives market, compared to sixty-seven percent in the previous survey. At the same time, the credit market has witnessed several major credit events in the last few years, such as defaults by Argentina, Enron, and WorldCom, to name a few.

The fast emergence of the default swap market and the major default events combined have provided an excellent platform to explore the expectations of the credit market embedded in default swap prices. In particular, it is tempting to ask the following questions: What were the default probabilities, both risk-neutral and physical, expected by the credit market during different periods before an eventual default? What was the expected rate of recovery in the underlying reference debt given default? How does a default swap model perform over different phases of period ahead of default? How did the default likelihoods implicit in ratings assigned to troubled debts by thirdparty rating agencies compare to market expectations? Did the rating agencies lead or lag the credit market in downgrading the debts? What economic and financial factors are potentially important in pricing default swaps? While the literature has seen a growing list of articles on the valuation of default swaps, there have been few empirical investigations in this regard. ${ }^{2}$

The purpose of this article is to fill in this gap and look for answers to those empirical questions in the case of Argentina default. To this goal, we first propose a valuation framework for credit default swaps which is flexible enough to disentangle the default probabilities from the expected recovery rate, allow correlation between underlying state variable processes, and at the same time, accommodate counterparty default risk. We next develop a parsimonious three-factor parametric default swap model, which takes into account effects of both economy-wide factors and name-specific variable on the pricing of default swaps on the Argentine sovereign debts. In the model, we relate the hazard rate of the Argentine sovereign debt to the three state variables, and explicitly specify market prices of risk. ${ }^{3}$ We then implement the model to a unique data set of credit default swaps on Argentine sovereign debt, and study the expectations about the default prospect of Argentine sovereign debts on the credit market.

\footnotetext{
${ }^{1}$ Risk, February 2003.

${ }^{2}$ See Aonuma and Nakagawa (1998), Chen and Soprazenti (2003), Cheng (1999), Das and Sundaram (2000), Duffie (1999a), Hull and White (2000a), Hull and White (2000b), Jarrow and Yildirim (2002), among others. Recent empirical work include Cossin, Hricko, Aunon-Nerin and Huang (2002), Houweling and Vorst (2001), and Hull, Predescu and White (2003).

${ }^{3}$ The hazard rate at time $\mathrm{t}$ can be viewed roughly as the instantaneous likelihood of default conditional on no default prior to time $t$.
} 
To estimate the parameters of the state variable processes and the default parameters of the model simultaneously, we adopt a one-step quasi-maximum likelihood procedure, in which both cross-sectional and time-series prices of default swaps on Argentine sovereign debts are used in constructing the likelihood function. Since both cross-sectional and time-series price information are employed in the estimation, the procedure is able to separately estimate the parameters of the physical processes and that of the market prices of risk. To take advantage of the widely available high-quality term structure of interest rate data, we also include U.S. interest rate swap data in the estimation. One of the strengths of our empirical study is the richness of our Argentine default swap data set, which includes 149 weekly observations of closing mid-market quotes from February 1999 to December 2001 on 10 contracts with maturities ranging from 1 to 10 years, with a total of 1490 weekly default swap quotes.

Our empirical investigation leads to the following overall assessment on the pricing performance of the model. First, our default swap model generally fits the data well. Except for contracts of very short maturities, the mean absolute pricing errors are in the range of 10 to 20 basis points. Second, except for the 1- and 2-year maturities, the model performs well out-of-sample before March of $2001 .^{4}$ On the other hand, as expected, the model performance deteriorates significantly as time approaches the date of eventual default in December 2001. On average, the mean absolute pricing errors has risen about ten times over a little more than a half-year period from March of 2001 to October of 2001. Third, judged by the signs of the pricing errors, the model seems to consistently underprice short maturity contracts and overprice medium maturity contracts. For the long maturities, however, the model underprices them in the early phase of the sample period, while oveprices them in the later part of the period. Taken together, there seems to be some kinds of "smile" effect in the pricing of the default swaps.

Based on the estimates of the parameter set, the physical and risk-neutral default probabilities are backed out from default swap prices, from which we can make several claims on the market expectations during the sample period. First, the risk-neutral default probability was always higher than its physical counterpart. Moreover, both the physical and risk-neutral default probabilities rose dramatically over the course of the sample period towards the eventual date of default. For example, the median 1-year physical default probability in the early phase of the sample period was $4.67 \%$, while the statistic for its risk-neutral counterpart was 5.50\%. Prior to March 2001, the 1-year physical default probability stayed below the $10 \%$ level, with lows around $1.5 \%$, and it eventually jumped to over $50 \%$ at the end of the sample period. Second, the wedge between the risk-neutral and the physical default probabilities was affected by changes in the the business cycle, the U.S. and Argentine credit conditions, and the overall strength of the Argentine economy. Third, major rating agencies, such as Moody's and Standard and Poor's, seemed to have assigned over-generous ratings to the Argentine debt, and they lagged the credit market in downgrading the

\footnotetext{
${ }^{4}$ To better study the model performance during different phases leading to eventual Argentine default, the whole sample period is split into three sub-periods: (1) the normal period: from 02/03/1999 to 03/14/2001, (2) the transition period: from $03 / 21 / 2001$ to $06 / 27 / 2001$, and (3) the crisis period: from $07 / 05 / 2001$ to $12 / 05 / 2001$. See data section for more details.
} 
debt. Compared to Moody's, S\&P gave even more overly optimistic view on Argentine sovereign debt throughout the sample period.

We also investigate the likely economic forces that drive Argentine credit default swap premiums. Correlation analysis shows that the first extracted economy-wide factor of the model is closely correlated to the negative slope of the U.S. term structure, and the second economy-wide factor is highly correlated to the level of the term structure at the long end. The implied name-specific distress factor is found to be highly correlated with the JP Morgan EMBI bond spread index for Argentina with a correlation coefficient of 0.986 , while there is not much correlation between the extracted name-specific factor and the return on the Merval stock index of Argentina. This result seems to suggest that, in proxying the country-specific factor for sovereign debts, the EMBI spread index would be a good candidate, while the return on the stock index is probably not an ideal choice. Finally, analysis of pricing errors shows that, there appears to be a common factor affecting both the U.S. and Argentine credit markets.

The rest of the article proceeds as follows. Section 2 presents the framework on credit default swap valuation. Section 3 develops the parametric three-factor default swap model. Section 4 discusses data sample and estimation strategy. In section 5, we report the parameter estimates, the in-sample fit and the out-of-sample pricing performances, and examine the market expectations implied in Argentine default swap prices. Section 6 provides the specification analysis on state variables and pricing errors. Section 7 concludes. All proofs of results and related formulas are provided in the Appendix.

\section{Credit Default Swap Valuation}

In this section, we propose a valuation framework for a plain vanilla binary credit default swap (CDS), in which default either by the underlying reference debt or by the CDS seller are considered. That is, there are two credit events that may occur before the expiration of the CDS contract, that is either default by the underlying reference debt or the CDS seller may default on its own debts. Essentially, we have a situation similar to a first-to-default credit event basket, which features valuation of contingent claims whose payoff depends not only on the timing of the first credit event, but also on the identity of the first event. Though it can easily be relaxed, we make the simplifying assumption that the CDS premium is paid continuously. In this setting, the buyer of the CDS contract will continue to pay the premium to the seller until any one of the following events occurs first: default by the underlying reference, default by the CDS seller on its own debts, or the expiration of the CDS contract.

Fix a probability space $(\Omega, \mathcal{G}, Q)$, with filtration $\mathcal{G}:=\left\{\mathcal{G}_{t} \mid 0<t<T\right\}$ satisfying $\mathcal{G}_{T}=\mathcal{G}$ that is complete, increasing and right continuous, where $Q$ is the equivalent martingale measure in the sense of Harrison and Kreps (1979). We also take as given a "locally" risk-free process $r$. Let $\chi_{1}(t)=1_{\xi_{1} \geq t}$ be the default indicator function of the underlying reference, and $\chi_{2}(t)=1_{\xi_{2} \geq t}$ be the CDS seller default indicator function, where $\xi_{1}$ and $\xi_{2}$ are respectively the stopping times that 
characterizes time of default by the underlying reference and by the CDS seller. The relevant stopping time of this first-to-default credit event basket is $\xi=\min \left\{\xi_{1}, \xi_{2}\right\}$, with corresponding credit event indicator function $\chi(t)=1_{\xi \geq t}$. An intensity process $h(t)$ for a stopping time $\xi$ is characterized by the property that the following is a martingale,

$$
\chi(t)-\int_{0}^{t}\left(1-\chi\left(u_{-}\right)\right) h(u) d u .
$$

For a plain vanilla binary credit default swap, there are two "legs": the premium leg (i.e., the stream of CDS premiums), and the default protection leg. The CDS buyer will continue to pay the premium until the maturity of the default swap or the time that the first credit event occurs. By a standard argument, the present value of the premium leg is:

$$
E^{Q}\left\{\int_{t}^{t+\tau} \frac{B(t)}{B(u)}\left(1-\chi\left(u_{-}\right)\right) p_{\tau} d u \mid \mathcal{G}_{t}\right\}
$$

where $B(t):=e^{\int_{0}^{t} r(s) d s}$ is the money market account with local risk free rate process $r(t)$ and $p_{\tau}$ is the continuous premium paid by the CDS buyer for default swap contract with maturity $\tau$. The expectation is taken under the equivalent martingale measure $Q$. The existence of an equivalent martingale measure implies the absence of arbitrage.

For the default protection leg, we make the conventional assumption that, if the first credit event (before the expiration of the default swap contract) happens to be default by the underlying reference, the default swap buyer will get payoff $w_{1}$ from the CDS seller for each unit face value of the underlying reference debt. If the CDS seller defaults on its own debts before default by the underlying reference of the CDS, then the default swap contract will terminate with the CDS buyer receiving no payment (i.e. $w_{2}=0$ ) from the seller. ${ }^{5}$ In this scenario, the default swap buyer can simply walk away from the contract and buy protection from another CDS seller on the market for the remaining time to maturity of the original default swap contract. To be precise, we are pricing a contingent claim that pays off at random time $\xi=\min \left\{\xi_{1}, \xi_{2}\right\}$, the first of two credit events, a contingent amount $w_{i}$ if $\xi=\xi_{i}$. The payoff process of the default protection is (see Duffie (1999b))

$$
\begin{aligned}
d D(t) & =\left(1-\chi\left(t_{-}\right)\right)\left[w_{1} d \chi_{1}(t)+w_{2} d \chi_{2}(t)\right] \\
& =\left(1-\chi\left(t_{-}\right)\right) w_{1}(t) d \chi_{1}(t) \\
& =\left(1-\chi\left(t_{-}\right)\right) y_{1}(t) h_{1}(t) d t+d M_{D}(t)
\end{aligned}
$$

where $M_{D}(t)$ is a martingale with respect to $Q$, and $y_{1}(t)$ can be viewed as the risk-neutral expected payment, conditional on all information up to but not including time $t$, that is $y_{1}(t)=E^{Q}\left[w_{1} \mid \mathcal{G}_{t_{-}}\right]$.

\footnotetext{
${ }^{5}$ Though easily relaxed, we are making the implicit assumption that there is no default by the CDS buyer. We also assume default by CDS seller on its other debts is exogenous to CDS seller.
} 
The present value of the payoff at default from the protection leg can then be expressed as

$$
E^{Q}\left\{\int_{t}^{t+\tau} \frac{B(t)}{B(u)}\left(1-\chi\left(u_{-}\right)\right) y_{1}(u) h_{1}(u) d u \mid \mathcal{G}_{t}\right\}
$$

By the fact that the net present value of a CDS at its initiation is zero, the fair-value CDS premium can be obtained by equating the values of the two legs,

$$
p_{\tau}=\frac{E^{Q}\left\{\int_{t}^{t+\tau} \frac{B(t)}{B(u)}\left(1-\chi\left(u_{-}\right)\right) y_{1}(u) h_{1}(u) d u \mid \mathcal{G}_{t}\right\}}{E^{Q}\left\{\int_{t}^{t+\tau} \frac{B(t)}{B(u)}\left(1-\chi\left(u_{-}\right)\right) d u \mid \mathcal{G}_{t}\right\}}
$$

We further assume that there is zero probability that both the CDS seller and the underlying reference of the CDS default at exactly the same instant of time. It can be shown that, given that the entity $E^{Q}\left\{e^{-\int_{t}^{u} h(s) d s} \mid \mathcal{G}_{t}\right\}$ jumps with probability zero, the following relation holds (see Duffie (1999b)):

$$
E^{Q}\left\{\left(1-\chi\left(u_{-}\right)\right) \mid \mathcal{G}_{t}\right\}=E^{Q}\left\{e^{-\int_{t}^{u} h(s) d s} \mid \mathcal{G}_{t}\right\}
$$

which immediately implies that (4) can be re-expressed as

$$
p_{\tau}=\frac{E^{Q}\left\{\int_{t}^{t+\tau} y_{1}(u) h_{1}(u) e^{-\int_{t}^{u}\left(r(s)+h_{1}(s)+h_{2}(s)\right) d s} d u \mid \mathcal{G}_{t}\right\}}{E^{Q}\left\{\int_{t}^{t+\tau} e^{-\int_{t}^{u}\left(r(s)+h_{1}(s)+h_{2}(s)\right) d s} d u \mid \mathcal{G}_{t}\right\}} .
$$

Equation (6) states that, given the processes for the interest rate $r(t)$, default arrival intensities $h_{1}(t)$ and $h_{2}(t)$, and the expected loss at default $y_{1}(t)$, the ratio of these two conditional expectations gives the fair-market CDS premium at the initiation of the contract. It should be noted that, above valuation framework does not impose any restrictions on the correlation between the stochastic processes of the short interest rate, the default arrival intensities, and the expected recovery payout at default. Nor does it assume independence between the default indicator functions for the underlying reference and the CDS seller. It is also worth pointing out that our framework nests as a special case the scenario that there is no default by the default swap seller, in which the hazard rate process associated with default by swap seller $h_{2}(t)$ can simply be set to zero. The valuation framework permits parameterizations that are able to separately identify the default intensity process $h_{1}(t)$ and the expected loss at default $y_{1}(t)$ for the underlying reference debt (see Bakshi, Madan and Zhang (2001b)).

Our next step is to specify the stochastic processes for the interest rate $r(t)$, hazard rates $h_{1}(t)$ and $h_{2}(t)$, and the expected payoff at default $y_{1}(t)$, and solve for the corresponding conditional expectations in (6). 


\section{A Parametric Default Swap Model}

In this section, we present a three-factor credit default swap model, which allows flexible correlation structure between processes of the interest rate, hazard rates, and the expected payoff at default. The model is adapted from the standard reduced-from framework such as Duffie and Singleton (1999), Jarrow and Turnbull (1995), Lando (1998), and Madan and Unal (1998).

Following Pearson and Sun (1994), and Duffee (1999), we first specify the instantaneous default free interest rate process as the sum of a constant and two economy-wide stochastic variables, $X_{1}(t)$ and $X_{2}(t)$, that each follows a CIR type squared-root process:

$$
\begin{aligned}
r(t) & =\alpha_{r}+X_{1}(t)+X_{2}(t), \\
d X_{i}(t) & =\kappa_{i}\left(\theta_{i}-X_{i}(t)\right) d t+\sigma_{i} \sqrt{X_{i}(t)} d W_{i}(t), i=1,2
\end{aligned}
$$

where $W_{1}(t)$ and $W_{2}(t)$ are standard Brownian motions and are independent from each other.

We also assume that there is a name-specific distress variable, $Z(t)$, associated with the underlying reference bond, which follows a squared-root process of its own,

$$
d Z(t)=\kappa_{z}\left(\theta_{z}-Z(t)\right) d t+\sigma_{z} \sqrt{Z(t)} d W_{z}(t)
$$

where $W_{z}(t)$ is a standard Brownian motion independent from $W_{1}(t)$ and $W_{2}(t)$. This name-specific distress variable can be viewed as representing the name-specific component of default risk which is closely correlated to the financial distress of the borrower. For example, for a corporate borrower, this variable can be related to the leverage ratio of the firm (Bakshi, Madan and Zhang (2001a)). For a sovereign borrower, it may be associated with the debt/GDP ratio or other variables that capture the country's inability to honor its debt obligations.

By assuming that the stochastic discount factor also follows a specific squared-root process, the state variables in the economy, $X_{1}(t), X_{2}(t)$, and $Z(t)$ can be shown to follow, under the equivalent measure, the following dynamics ${ }^{6}$,

$$
\begin{aligned}
d X_{i}(t) & =\left[\kappa_{i} \theta_{i}-\left(\kappa_{i}+\lambda_{i}\right) X_{i}(t)\right] d t+\sigma_{i} \sqrt{X_{i}(t)} d \widetilde{W}_{i}(t), i=1,2 \\
d Z(t) & =\left[\kappa_{z} \theta_{z}-\left(\kappa_{z}+\lambda_{z}\right) Z(t)\right] d t+\sigma_{z} \sqrt{Z(t)} d \widetilde{W}_{z}(t),
\end{aligned}
$$

where $\widetilde{W}_{1}, \widetilde{W}_{2}$, and $\widetilde{W}_{z}$ are independent standard Brownian motions under the equivalent martingale measure $Q$.

Following Duffee (1999) and Bakshi et al. (2001a), we make the convenient assumption that

${ }^{6}$ The dynamics of the stochastic discount factor, $\Psi(t)$, is as follows,

$$
\frac{d \Psi(t)}{\Psi(t)}=-r(t) d t-\Sigma d W(t)
$$

where $\Sigma$ is a $3 \times 3$ diagonal matrix with diagonal elements, $\frac{\lambda_{1}}{\sigma_{1}} \sqrt{X_{1}(t)}, \frac{\lambda_{2}}{\sigma_{2}} \sqrt{X_{2}(t)}$, and $\frac{\lambda_{z}}{\sigma_{z}} \sqrt{Z(t)}$, and $W(t)=$ $\left(W_{1}(t), W_{2}(t), W_{z}(t)\right)^{\prime}$. 
the hazard rate of the underlying reference bond, $h_{1}(t)$, is linear in the three state variables in the economy:

$$
h_{1}(t)=\Lambda_{0}+\Lambda_{x_{1}} X_{1}(t)+\Lambda_{x_{2}} X_{2}(t)+Z(t),
$$

where $\Lambda_{0}>0$, and the parameters $\Lambda_{x_{1}}$, and $\Lambda_{x_{2}}$ reflect correlation between the hazard rate and the interest rate.

Since most default swap sellers are big financial institutions whose financial welfare are not directly linked to a particular underlying reference debt, it is reasonable to assume that the hazard rate of the default swap seller, $h_{2}(t)$, does not depend on the name-specific distress variable $Z$, rather it is a linear function of the two economy-wide factors,

$$
h_{2}(t)=\varphi_{0}+\varphi_{x_{1}} X_{1}(t)+\varphi_{x_{2}} X_{2}(t) .
$$

Observe that from (6) and (12), our default swap model will collapse into the case of no counterparty default if the default intensity process of the default swap seller, $h_{2}(t)$, is zero.

To keep the model parsimonious, we assume that the conditional expected loss at default, $y_{1}$, dose not depend on any of the three state variables. ${ }^{7}$ However, even under this convenient assumption, our approach improves from the previous literature since it is potentially able to separately identify the expected recovery rate and the default probability from the default swap prices. ${ }^{8}$ The dynamics of the state variables, as specified in (7) to (9), and the hazard rate specifications (plus the default recovery) completely determine the valuation process of the financial securities in our default swap model.

Following the ideas of Bakshi and Madan (1999) and Duffie, Pan and Singleton (1999), we define the characteristic function as in the following, ${ }^{9}$

$$
\Phi(t, \tau ; \phi):=E_{t}^{Q}\left[e^{-\int_{t}^{t+\tau}\left[r(s)+h_{1}(s)+h_{2}(s)\right] d s+i \phi h_{1}(t+\tau)}\right],
$$

subject to the boundary condition, $\Phi(t+\tau, 0 ; \phi)=e^{i \phi h_{1}(t+\tau)}$. The following proposition gives the analytical solution of this characteristic function $\Phi(t, \tau ; \phi)$, and the credit default swap premium expressed in terms of $\Phi(t, \tau ; \phi)$ (see the Appendix for proof).

Proposition 1 Let the interest rate process follow (7)-(8), name-specific distress factor follow (9), and default arrival intensities for the underlying reference and default swap seller be of (11) and (12). Given the characteristic function, $\Phi(t, \tau ; \phi)$, defined as in (13), we have:

1. The characteristic function $\Phi(t, \tau ; \phi)$ can be analytically solved as:

$$
\Phi(t, \tau ; \phi)=e^{\mathcal{A}(t, \tau ; \phi)-\mathcal{B}(t, \tau ; \phi) X_{1}(t)-\mathcal{C}(t, \tau ; \phi) X_{2}(t)-\mathcal{D}(t, \tau ; \phi) Z(t)},
$$

\footnotetext{
${ }^{7}$ This restriction can easily be relaxed, where one possible specification would be assuming that the recovery rate is a function of the state variables, $y_{1}=w_{0}+w_{1} e^{\beta_{1} X_{1}(t)+\beta_{2} X_{2}(t)+\beta_{3} Z(t)}$, but at the cost of adding several more parameters.

${ }^{8}$ For example, Jarrow and Yildirim (2002) follow Duffie-Singleton approach, so the recovery and default probability are inherently not separable.

${ }^{9}$ See Bakshi and Madan (1999), and Duffie et al. (1999).
} 
with

$$
\begin{aligned}
\mathcal{A}(t, \tau ; \phi) & =\mathcal{A}_{1}(t, \tau ; \phi)+\mathcal{A}_{2}(t, \tau ; \phi)+\mathcal{A}_{3}(t, \tau ; \phi)-\left(\alpha_{r}+\Lambda_{0}+\varphi_{0}\right) \tau+i \phi \Lambda_{0}, \\
\mathcal{B}(t, \tau ; \phi) & =\frac{-i \phi \Lambda_{x_{1}}\left[\gamma_{1} \operatorname{coth}\left(\frac{\gamma_{1} \tau}{2}\right)-\left(\kappa_{1}+\lambda_{1}\right)\right]+2\left(1+\Lambda_{x_{1}}+\varphi_{x_{1}}\right)}{\gamma_{1} \operatorname{coth}\left(\frac{\gamma_{1} \tau}{2}\right)+\left[\left(\kappa_{1}+\lambda_{1}\right)-i \phi \Lambda_{x_{1}} \sigma_{1}^{2}\right]}, \\
\mathcal{C}(t, \tau ; \phi) & =\frac{-i \phi \Lambda_{x_{2}}\left[\gamma_{2} \operatorname{coth}\left(\frac{\gamma_{2} \tau}{2}\right)-\left(\kappa_{2}+\lambda_{2}\right)\right]+2\left(1+\Lambda_{x_{2}}+\varphi_{x_{2}}\right)}{\gamma_{2} \operatorname{coth}\left(\frac{\gamma_{2} \tau}{2}\right)+\left[\left(\kappa_{2}+\lambda_{2}\right)-i \phi \Lambda_{x_{2}} \sigma_{2}^{2}\right]} \\
\mathcal{D}(t, \tau ; \phi) & =\frac{-i \phi\left[\gamma_{3} \operatorname{coth}\left(\frac{\gamma_{3} \tau}{2}\right)-\left(\kappa_{z}+\lambda_{z}\right)\right]+2}{\gamma_{3} \operatorname{coth}\left(\frac{\gamma_{3} \tau}{2}\right)+\left[\left(\kappa_{z}+\lambda_{z}\right)-i \phi \sigma_{z}^{2}\right]}
\end{aligned}
$$

where $\mathcal{A}_{1}(t, \tau ; \phi)-\mathcal{A}_{3}(t, \tau ; \phi)$, and $\gamma_{1}-\gamma_{3}$ are provided in the Appendix.

2. Given the characteristic function in (14), the credit default swap premium in (6) can be expressed as

$$
p_{\tau}=\frac{\left.y_{1} \int_{t}^{t+\tau} \frac{1}{i} \frac{\partial \Phi(t, u ; \phi)}{\partial \phi}\right|_{\phi=0} d u}{\int_{t}^{t+\tau} \Phi(t, u ; \phi=0) d u}
$$

where $\Phi(t, u ; \phi=0)$ and $\left.\frac{\partial \Phi(t, u ; \phi)}{\partial \phi}\right|_{\phi=0}$ are respectively, $\Phi(t, u ; \phi)$ and the derivative of $\Phi(t, u ; \phi)$ with respect to $\phi$ evaluated at $\phi=0$, whose expressions are given in the Appendix.

The above proposition shows that the characteristic function defined in (13) synthesizes the problem of credit default swap valuation. This is not surprising since the characteristic function possesses the information about the distribution of the remaining uncertainty of the underlying state variables. It is straight-forward to show that, given the characteristic function, the zerocoupon default-free bond price in this economy, $B(t, \tau)=E_{t}^{Q}\left[e^{-\int_{t}^{t+\tau} r(s) d s}\right]$, can be obtained by evaluating the characteristic function at some particular parameter values.

In the remainder of the paper, we implement the parametric credit default swap model to a sample of credit default swaps on Argentine sovereign debt from February 1999 to December 2001. Our empirical investigation focuses on the following questions, (i) How does our default swap model perform on Argentine default swaps, as measured by in- and out-of-sample pricing errors? (ii) What were the implied probabilities of default, both physical and risk-neutral, of the Argentine sovereign debt expected by the credit market over the course of the sample period? (iii) What was the expected recovery rate implicit in the prices of the credit default swaps? (iv) Did the third party rating agencies, such as Moody's and Standard and Poor's downgrade Argentine debt in a timely manner? How did the default likelihoods implicit in ratings assigned to Argentine sovereign debt by rating agencies compare to market expectations? (v) What are the likely underlying economic factors that drive the prices of default swaps on Argentine sovereign debts?

In discussing possible model mis-specifications and related empirical issues, we take the stand throughout the paper that the market fairly prices credit default swap and other related securities. 


\section{Data and Estimation Strategy}

In this section, we discuss the data of credit default swaps on Argentine sovereign debts and the empirical strategy for estimating our default swap model.

\subsection{Default Swap Data}

The raw data of default swaps on Argentine sovereign debt used in our study include daily closing mid-market quotes from JP Morgan's trading desk on 10 contracts with maturities ranging from 1- to 10- years. The default premium (paid quarterly) is quoted as a percentage of the notional amount. The data sample covers the period from January 28, 1999 to December 05, 2001, with 739 daily observations and a total of 7390 default swap quotes. The advantage of the data set is that there is a "True" or "False" flag for each observation, indicating whether the quotes on a particular day were true quotes from JP Morgan Chase, or they are just some stalled quotes left over from previous trading days. Accordingly, we delete all observations with a "False" flag, and keep only those with a "True" indicator. This screening leaves us with 689 observations, and a total of 6890 default swap quotes. To reduce noise from the daily observations, we construct the corresponding weekly data series from the daily series of credit default swap quotes by picking observations on each Wednesday only (or on Thursday for this matter if there is no data on a particular Wednesday). The resulting sample includes 149 weekly observations from February 03, 1999 to December 05, 2001, with a total of 1490 price quotes. This weekly data sample provides the basis for our empirical analysis that follows.

Figure 1 shows the evolution of the term structure of the premium of default swaps on Argentine sovereign debts over the sample period. Two observations can be made. First, for the majority of the sample period before March 2001, the short end of the term structure of default swap premium were in the range of 3 - 7 percent, while the long end were in the 5 - 9 percent range. Exception was a brief blip in November 2000, where the default swap premium on short contracts jumped over 10 percent. However, since mid-March of 2001, the default swap premium on short contracts spiked to the magnitude of over 10 percent, and further jumped to the magnitudes of 30-40 percent in mid-July 2001, and eventually reached 60-70 percent level. Second, the slope of the term structure of default premium changed over the course of the sample period. It was upward-sloping most of time before March 2001, except the brief reversal in November 2000. After March 2001, however, the default swap premium turned into downward-sloping. This pattern is roughly consistent with previous evidences that, the term structures of the credit spread of junk bonds are usually downward-sloped, while it is upward-sloping for investment grade bonds and flat for bonds with medium credit qualities (see Fons (1994) and Sarig and Warga (1989)).

A brief review of the recent history of the political and economic events in Argentina provides clues to the evolution of the premiums of default swaps on Argentine sovereign debt during our

sample period. ${ }^{10}$ Since the last quarter of 1998, the prospect of an economic recession was looming

\footnotetext{
${ }^{10}$ For more details, see Mussa (2002) and Pando (2002).
} 
for Argentina. At the same time, the Russian default and devaluation on September 1998 and especially the collapse of Brazil's exchange-rate-based stabilization program, the Real Plan, in mid-January 1999 affected Argentina negatively. As the situation in Brazil calmed down in the spring of 1999, Argentina successfully floated a substantial amount of sovereign debts during much of 1999 and the first half of 2000. However, the continuing recession in the Argentine economy was depressing tax revenue and at the same time, increasing compensatory social spending, contributing to deteriorating fiscal situation. Conditions worsened during the second half of 2000 as the recession continued and the lack of political initiative of the newly elected President Fernando de la Rua undermined confidence. By late October of 2000, it appeared that the fiscal deficit target in the IMF-supported program might be missed. Investors began to turn pessimistic about Argentina's ability to pay its debt. An IMF-led support package of $\$ 40$ billion calmed the market briefly at the beginning of 2001.

However, with revenues well below expectation and expenditures not contained, by February 2001, it became clear that the fiscal target for the first quarter of 2001 was at risk, following the miss for the last quarter of 2000. Under heightened political tensions, President de la Rua removed Minister of Economy Machinea and appointed Lopez Murphy to the post in early March of 2001. Within days, he proposed a fiscal austerity program focused on sharp reduction in public spendings, which was immediately rejected by the vast majority of Argentine political forces including the parties of the ruling coalition. This event marked the effective end to any realistic hope that the Argentine government would address its fiscal difficulties with sufficient resolve to avoid sovereign default. As a result, Lopez Murphy resigned and the president chose Domingo Cavallo, author of the Convertibility Plan, as the new minister. Cavallo focused on the revenue side rather than cutting expenditures, but the measures failed to boost the confidence of the market. In the face of deteriorating market confidence during the spring of 2001, Minister Cavallo pursued numerous new initiatives, including modification of the Convertibility Plan, by pegging the peso $50 \%$ to the dollar and $50 \%$ to the euro, and set up a system of multiple exchange rates. Another initiative concerned the removal of the governor of the Central Bank, which further undermined market confidence. Perhaps the most important initiative by Cavallo was the massive voluntary swap of Argentina's public debt in May 2001, intended to replace interest and principal payments due between 2001 and 2005 with substantially higher interest and principal payments due over the next 25 years.

In late June and early July of 2001, disappointing tax revenues and massive deposit withdrawals from Agentine banks pushed the spreads on Argentine sovereign debts to around 1500 basis points, as measured by the EMBI. To halt the bank run and the depletion of reserves, the government announced a zero-deficit plan, which was impractical but nonetheless was endorsed by the IMF. Negative parliamentary and provincial elections in mid-October for the ruling party eliminated any hope for austerity measures needed to implement the zero-deficit policy. Tax revenues dwindled due to shrinking economic activity and tax evasion. By mid-November, withdrawals of bank deposits and losses of foreign exchange reserves accelerated, and IMF finally refused to lend any more support. By mid-December, Cavallo resigned from his post, followed by President de la Rua a few 
days later. On December 23rd, 2001, the interim president Rodriguez Saa formally announced the Argentine default.

Among numerous events mentioned above, two of them stand out in their significance. The first is the rejection of Lopez Murphy's austerity plan in March of 2001, which signaled the end of any realistic chance that Argentine government had the political resolve and power to achieve the fiscal discipline needed to avoid a sovereign default. Another event was the large scale withdrawals of deposit from Argentine banks in late June and early July of 2001, which led to eventual total collapse of the financial system and market confidence. An examination of changes in the default premiums confirms our assessment. Before March 14 of 2001, the default swap premiums were rarely above 10 percent level. After March 14 of 2001, however, the default swap premium jumped above 10 percent for good. Another big jump occurred at the beginning of July 2001. This suggests that the whole sample period can be split into three sub-periods: (1) the normal period: from the start of the sample period to $03 / 14 / 2001$, (2) the transition period: from $03 / 21 / 2001$ to $06 / 27 / 2001$, and, (3) the crisis period: from 07/05/2001 to the end of the sample period.

Table 1 shows the statistics of the credit default swap premium on Argentine sovereign debt over the three sub-periods. Several observations are in order. First, the magnitude of the default swap premium in the three sub-periods are vastly different. The average premium on 1-year default swap is 4.35 percent for the normal period, while it is 12.53 percent for the transition period, and 45.69 percent for the crisis period. Second, the term structure of the default swap premium is upward-sloping in the normal period, while it is downward-sloping in the transition period and even more so in the crisis period. Third, as shown by the standard deviations, for all three subperiods, there are more variation at the short end of the term structure of default swap premium. For example, the standard deviation of the premium for the 1-year contract is 1.71 percent in the normal period, while it is 1.36 percent for the 10-year contract. Finally, for all three periods, the default premiums are positively skewed. As for the excess kurtosis, it is negative in the normal period (except the 1-year contract) and the crisis period. For the transition period, the default premiums have a positive excess kurtosis in the short maturities, but a negative excess kurtosis in longer contracts.

\subsection{Estimation Strategy}

In the empirical implementation, we estimate the parameters of the term structure of interest rate and that of the default swap process simultaneously in a single step, using a standard quasimaximum likelihood (QML) method widely used in the empirical term structure of interest rate literature (for similar treatment, see Chen and Scott (1993), Duffie and Singleton (1997), Duffee (2002), and Pearson and Sun (1994)). One way to estimate the parameters of the term structure of interest rate and that of the default swap process is to carry out the estimation based on credit default swap data only, without using any U.S. interest rate data. Alternatively, one can estimate the model parameters, utilizing both credit default swap data and the U.S. interest rate data. We follow the latter approach to take advantage of the widely available rich and high-quality U.S. term 
structure of interest rate data.

We use the plain-vanilla fixed for float U.S.-dollar LIBOR-quality interest rate swap yields as the basis for the U.S. term structure of interest rate (see Dai and Singleton (2000), and Duffie, Pedersen and Singleton (2002)). There are two reasons for this choice. First, although Treasury yields have widely been used as benchmarks for risk-free term structure of interest rates in the past, there have been serious concerns about whether Treasury yields should still be viewed as the benchmark due to the dwindling trading in Treasury securities since 1998. Furthermore, Treasury rates also differ from the "true" risk-free rates because of such factors as the repo effects, liquidity differences, and tax shields (see Collin-Dufresne and Solnik (2000), and Duffie and Singleton (1997)). For this reason, U.S.-dollar LIBOR-quality swap yields have gained popularity among both practitioners and academia as the new benchmark of the risk-free reference rates. Second, interest rate swaps data are widely available at a range of constant times to maturity, which makes estimation process less than complicated. Although swaps are defaultable in theory, the effects of the counterparty default risk of swap contracts are believed to be minimal because of the institutional standardization of the interest rate swap market (see Duffie et al. (2002)).

Under the assumption of interest rate swaps being default-free, the fair-value swap rate with maturity $\tau_{m}$ at its initiation is (see Duffie and Singleton (1997)):

$$
c_{t}^{m}=\frac{1-B\left(t, \tau_{m}\right)}{\sum_{j=1}^{2 \tau_{m}} B\left(t, \frac{j}{2}\right)}
$$

where $B\left(t, \frac{j}{2}\right)$ is the risk-free zero coupon bond price with time to maturity $\frac{j}{2}$. In our parametric default swap model developed in the previous section, the risk-free zero-coupon bond price $B\left(t, \frac{j}{2}\right)$ is the 2 -factor extended CIR bond price with time to maturity $\frac{j}{2}$.

Since the two underlying state variables in the reference term structure process, $X_{1}(t)$ and $X_{2}(t)$, are unobservable, we follow Chen and Scott (1993) and Duffie and Singleton (1997), by assuming that the 2- and 10-year swap yields are measured without error. That is, we assume for $\tau_{m}=2$, and 10, model-based swap rates are exactly the same as the market swap rates. Stack the two perfectly-observed 2- and 10-year interest rate swap yields at time $t$ in the vector $S_{t}=\left(s_{t}^{2}, s_{t}^{10}\right)^{\prime}$. Given the parameter set, implied state vector $\widehat{X}_{t}=\left(\widehat{X}_{1, t}, \widehat{X}_{2, t}\right)^{\prime}$ can be inverted numerically from $S_{t}$, using (20). The density of $S_{t}$ conditional on $S_{t-1}$ is

$$
f_{S}\left(S_{t} \mid S_{t-1}\right)=\frac{1}{\left|J_{t}^{S}\right|} f_{X}\left(\widehat{X}_{t} \mid \widehat{X}_{t-1}\right)
$$

where $f_{X}\left(X_{t} \mid X_{t-1}\right)$ is the conditional density of state vector $X_{t}$ given $X_{t-1}$ and $J_{t}^{S}$ is the Jacobian of the transformation at time $t$ which is non-linear and time-dependent. As we know, the conditional densities of the state variables $f_{X}\left(X_{t} \mid X_{t-1}\right)$, are non-central chi-square, as shown in Cox, Ingersoll and Ross (1985).

We also assume that the premium on the 5-year credit default swap, usually one of the most liquid contracts, is measured without error. Given the parameter set and the two economy-wide 
state variables $X_{1}(t)$ and $X_{2}(t)$, the implied process for the name-specific distress factor, $Z(t)$, can be inverted from $c_{t}^{5}$ as given in (19). Likewise, the density function of the 5-year default swap premium $c_{t}^{5}$ conditional on $c_{t-1}^{5}$ can be expressed as $\frac{1}{\left|J_{t}^{C}\right|} f_{Z}\left(Z_{t} \mid Z_{t-1}\right)$, where $J_{t}^{C}$ is the corresponding Jacobian of the 5 -year default swap premium. For the default swap contracts with maturities of 1-, 3 -, and 10-year, the swap yields are assumed to be measured with errors. Specifically, we assume that the nonzero measurement errors $\left\{\varepsilon_{t}\right\}$ of 1-, 3-, and 10-year default swap contracts are serially uncorrelated, but jointly normally distributed with zero mean and variance-covariance matrix $\Omega_{\varepsilon}$ (see Duffee (2002).

Under these assumptions, the log-likelihood function for a sample of observations on the perfectlyobserved 2- and 10-year interest rate swap yields, 5-year default swap premium, and the three imperfectly-observed (1-, 3-, and 10-year) default swap yields for $\mathrm{t}=2, \ldots, \mathrm{T}$, in the conditional maximum likelihood estimation is ${ }^{11}$,

$$
\begin{aligned}
L= & \sum_{t=2}^{T} \log f_{X}\left(\widehat{X}_{t} \mid \widehat{X}_{t-1}\right)-\sum_{t=2}^{T} \log \left|J_{t}^{S}\right|+\sum_{t=2}^{T} \log f_{Z}\left(\widehat{Z}_{t} \mid \widehat{Z}_{t-1}\right)-\sum_{t=2}^{T} \log \left|J_{t}^{C}\right| \\
& -\frac{3(T-1)}{2} \log (2 \pi)-\frac{T-1}{2} \log \left|\Omega_{\varepsilon}\right|-\frac{1}{2} \sum_{t=2}^{T} \varepsilon_{t}^{\prime} \Omega_{\varepsilon}^{-1} \varepsilon_{t},
\end{aligned}
$$

where expressions for $f_{x}\left(x_{t} \mid x_{t-1}\right), J_{t}^{S}$, and $J_{t}^{C}$ are given in the Appendix.

For the purpose of implementing the quasi-maximum likelihood method, we substitute the exact transition density $f_{x}\left(x_{t} \mid x_{t-1}\right)$ with a normal density: $x(t) \mid x(t-1) \sim N\left(\mu_{t}, Q_{t}\right)$, where $\mu_{t}$ and $Q_{t}$ are the first two moments of $x(t)$ given $x(t-1)$ which are given in the Appendix ${ }^{12}$. Given the large number of parameters in our credit default swap model, we set $\varphi_{x_{1}}$ and $\varphi_{x_{2}}$ in the hazard rate function of the default swap seller, $h_{2}(t)=\varphi_{0}+\varphi_{x_{1}} X_{1}(t)+\varphi_{x_{2}} X_{2}(t)$, to be zero in the empirical exercises. This is equivalent to assuming that the hazard rate of the default swap seller is constant. While this simplification takes away the time varying dependence of the default probability of the default swap seller on the economy wide factors, it still captures the first order effect of the counterparty default risk. To ensure the variance-covariance matrix $\Omega_{\varepsilon}$ of the pricing errors of the 1-, 3-, and 10-year default swap contracts be revertable, we assume that $\Omega_{\varepsilon}$, which is time-invariant, satisfies the Cholesky decomposition, $\Omega_{\varepsilon}=C C^{\prime}$, where $C$ is a $3 \times 3$ matrix with non-zero elements $C_{11}, C_{22}, C_{33}, C_{21}$ and $C_{32}$. The final parameter set to be estimated is, $\Theta=\left[\kappa_{1}, \theta_{1}, \sigma_{1}, \kappa_{2}, \theta_{2}, \sigma_{2}, \alpha_{r}, \lambda_{1}, \lambda_{2}, \kappa_{z}, \theta_{z}, \sigma_{z}, \lambda_{z}, \Lambda_{0} . \Lambda_{x_{1}}, \Lambda_{x_{2}}, \varphi_{0}, y_{1}\right]$, plus $C_{11}, C_{22}, C_{33}, C_{21}$ and $C_{32}$ in the Cholosky decomposition of the variance-covariance matrix $\Omega_{\varepsilon}$ of the normal densities for the three non-zero measurement errors.

\footnotetext{
${ }^{11}$ Alternatively, one can also include the log of the unconditional log likelihood to construct the exact log-likelihood function. Given that the conditional MLE and the exact MLE have the same large sample distributions, and that the conditional MLE provides consistent estimates under some circumstances while the exact MLE does not, I chose to use the conditional MLE method (see Hamilton (1994)).

${ }^{12}$ In the first attempt, I tried to estimate the model using the maximum likelihood method, based on the exact noncentral chi-square transition density. However, I found the exact non-central chi-square transition density function is far less stable than the approximate normal density function, so I report my result based on the QML estimation. See Zhou (2001) for similar evidences.
} 
The advantage of our empirical procedure is that, we incorporate both cross-sectional and time series information into the construction of the likelihood function, which makes it possible for us to separately identify the parameters of the state variables and that of the market prices of risk.

\section{$5 \quad$ Empirical Results}

In this section, we first discuss the parameter estimates and the in-sample fit of our credit default swap model. We then look at the out-of-sample pricing performance of the model during different sub-periods of sample. Finally, we analyze the market expectation of the default prospect of Argentine sovereign debt by computing the implied physical and risk-neutral default probabilities of the underlying reference during the sample period. Based on the calculated implied default probabilities, we examine whether the major rating agencies, such as Moody's and Standard and Poor's led or lagged the market in downgrading Argentina debt during the sample period.

\subsection{Parameter Estimates and In-Sample Fit}

As in previous studies, such as Duffee (1999) and Pearson and Sun (1994), the data are unable to produce a reliable estimate of $\alpha_{r}$. I follow their approach and set the adjustment factor $\alpha_{r}$ equal to a constant value -0.99 , which seems to produce the most stable estimates for the remaining parameters. In our numerous estimating efforts, the model seems to have difficulty pinning down the counterparty default probability of the default swap seller, $\varphi_{0}$, so we set it to be a constant at $0.75 \%$. Table 2 provides the parameter estimates of the default swap model in the quasi-maximum likelihood estimation and their asymptotic standard errors using 2- and 10-year interest rate swap and 1-, 3-, 5-, and 10-year default swap data from 02/03/1999 to 11/01/2000. The asymptotic standard errors reported are the robust "quasi-maximum likelihood" standard error proposed by White (1982). ${ }^{13}$

These reported statistics are informative about the internal working of the model. For the two term structure of interest rate factors, the estimates of the mean-reversion parameter of the first factor, $\kappa_{1}$, and $\kappa_{1}+\lambda_{1}$, show strong mean-reversion in the first factor. On the contrary, the estimate of the mean-reversion parameter of the second factor shows very weak mean reversion. The estimates of the risk premium for both factors are negative, though the risk premium for the first factor is of very small magnitude. The estimates of the long-term means of the two term structure of interest rate factors, $\theta_{1}$ and $\theta_{2}$, are respectively 0.946 and 0.153 , together with the adjustment factor, $\alpha_{r}=-0.99$, this implies an estimated long-run mean $\bar{r} \equiv \theta_{1}+\theta_{2}+\alpha_{r}$ of $r$, of $10.9 \%$. Even though our one-step estimation utilizes both term structure of interest rate data and default swap data, our estimation results on the term structure of interest rate processes are very much in line with previous studies in the literature whose estimation are based solely on term structure of interest rate data (see Chen and Scott (1993), Duffee (1999), Duffee (2002), Duffie

\footnotetext{
${ }^{13}$ The standard errors obtained using the usual Hessian matrix of the likelihood function are also computed. They are similar in magnitude to the QML standard errors and thus not reported.
} 
et al. (2002), Duffie and Singleton (1997), Pearson and Sun (1994)). As for the name-specific distress factor, the estimate of the mean-reversion factor, $\kappa_{z}$, shows that the mean-reversion in the name-specific distress factor is very weak. In fact, the estimate of the risk-neutral mean-reversion parameter, $\kappa_{z}+\lambda_{z}=-0.029$, is negative.

The estimates of the three sensitivity parameters in the hazard rate specification of the underlying reference debt shows that the hazard rate, $h_{1}(t)$, is negatively related to the first term structure factor, while it is positively related to the second factor. Since the first and the second factors extracted from data are shown (with details in later sections) to respectively be closely correlated with the negative slope of the term structure and the 10-year Treasury yield, this implies that the hazard rate of the underlying reference is positively related to both the slope of and the level at the long end of the term structure of interest rate. This result is consistent with the evidence that the likelihood of default is higher for risky bonds during economic down turns when the slope of the term structure is usually steep.

The estimate of the expected rate of payoff at default for the default swap holder is 0.726 , which implies a recovery rate for the underlying reference at 0.274 . For the sake of comparison, most previous studies in credit derivatives modeling assume a constant value for the recovery rate usually around 0.4 (see Duffee (1999), and Jarrow and Yildirim (2002)), and estimate other parameters based on this assumed recovery rate. Our framework nests the case of constant recovery as a special case. The estimates of the Cholesky decomposition of the variance-covariance matrix implies that the standard deviations for the pricing errors of the 1-, 3-, and 10-year default swaps are respectively, 0.0078, 0.0038, and 0.0055, with correlation coefficient between pricing errors of 1- and 3-year default swaps at 0.766, and that between 3- and 10-year default swaps at 0.288.

In sum, the parameter estimates of our model show strong mean-reversion in the first factor of term structure of interest rate, and weak mean-reversion in the second term structure factor, which is consistent with previous evidences in term structure of interest rate literature. The parameter estimates also show weak mean-reversion in the name-specific distress factor. In terms of hazard rate specification, the parameter estimates reveal that the implied instantaneous hazard rate is positively related with both the slope and the level at the long end of the term structure of interest rate.

The in-sample pricing errors are computed based on the parameter estimates reported in Table 2. Using estimates of the parameter vector, we calculate the model-determined default swap premium for each of the 9 default swap contracts (except the benchmark 5 -year contract which is measured without error). The pricing errors are then computed as the market prices minus the modeldetermined prices. The percentage pricing errors are calculated as the pricing errors divided by the corresponding market default swap premium.

Table 3 reports the in-sample pricing errors of our default swap model. In general, our default swap model fits the data well, as shown by the median pricing errors (MDPE) in the first row in Table 3. The median pricing errors for most maturities are in the magnitude of a few basis points. The signs of the median pricing errors show that our model slightly underprices default 
swaps on both the short and long ends of the maturity spectrum, while slightly overprices contracts at the middle of the maturity spectrum. This suggests there is some kind of "smile" effect in the pricing of the default swaps with respect to maturity in our model. The median percentage pricing errors (MDPPE) shown in third row of Table 3 confirm our observation. The median percentage pricing errors are less than $1.8 \%$ for most contracts. In terms of absolute pricing errors, the mean absolute pricing errors (MAPE) in the second row and the mean absolute percentage pricing errors (MAPPE) in the fourth row show that the model fits the default swap data very well for most of the maturities except the very short contracts. For most contracts, the mean absolute pricing errors are in the range of 10 to 20 basis points.

On the other hand, the absolute pricing errors for the 1-year contract is relatively large, which may be due to two reasons. First, there are high variation in the default swap premiums at the short end of the maturity, as manifested by the high standard deviation in the default swap premiums of the 1-year contract (shown in Table 1). Second, we use the 5-year default swap contract as the benchmark in our model, whose maturity is much longer than the 1-year contract, and this may add to the inferior pricing of the 1-year contract by our model. Given the choice of the benchmark 5 -year contract, the pricing performances of other maturities actually show how well the bench mark 5-year default swap contract together with the 2- and 10-year interest rate swaps span other contracts on the maturity curve of the default swaps. The results indicate that they do a decent job in pricing contracts with maturities longer than 2 years, while not as well in pricing the 1-year contract.

\subsection{Out-of-Sample Pricing Errors}

We have shown that our default swap model fits the data pretty well in-sample for most maturities. Because our sample period includes several vastly different phases leading to the eventual Argentina default, it would be interesting to know how the model would perform during those different subperiods. For this purpose, we examine the out-of-sample pricing performance of the model. When comparing pricing errors over different sub-periods, we should keep in mind that due to the dramatic political and economic development in Argentina after mid March 2001, the quality of the default swap quotes during the transition and crisis periods may not be as good as those during the normal period. Therefore, the pricing performances of the transition and crisis periods should be evaluated with caution.

In calculating the out-of-sample pricing errors, the parameters are kept constant as displayed in Table 2, which are estimated using the QMLE method described in previous section on data of selected interest rate swap and default swap contracts from 02/03/1999 to 11/01/2000. Based on those parameter estimates, we compute the out-of-sample model-determined default swap premium on all maturities using the contemporaneous 2-, and 10-year interest rate swap and 5-year default swap prices. The out-of-sample pricing errors at time-t are then calculated as the difference between the contemporaneous market default swap premium at time $t$ and the model-determined default swap premium at the same time. As shown in data section, our sample period includes months 
running up to the eventual Argentina default, and credit default premium swings wildly in the later part of the sample period. To better gauge the pricing performance of our model in different phases of the sample period, we split the out-of-sample period into three sub-periods and examine the results individually. The three out-of-sample sub-periods are respectively: (i) the normal period (11/08/00 - 03/14/01); (ii) the transition period (03/21/01 - 06/27/01); and (iii) the crisis period $(07 / 05 / 01-12 / 05 / 01)$.

Table 4 reports the out-of-sample pricing errors of our default swap model, where we can make the following conclusions. First, like the situation of in-sample fit, the model performs well in pricing default swaps out-of-sample in the normal period, except for the 1- and 2-year default swaps. For most maturities, the median pricing errors are at the magnitude less than 11 basis points, and the mean absolute pricing errors are less than 26 basis points. Measured by percentage terms, the median percentage pricing errors for most maturities are in the magnitude of less than 1.6\%. Similarly, for most contracts, the mean absolute percentage pricing errors are between $1.35 \%$ and $3.49 \%$. The out-of-sample pricing errors of our default swap model for the normal period are comparable to other models in literature, even though we have kept the model parameters constant in calculating the out-of-sample pricing errors without updating the parameters from period to period. Second, judged by the sign of the median pricing errors, the model seems to overprice default swap with maturities in the medium range in the normal period, while underprice contracts with short and long maturities, just like in the case of in-sample.

Third, as expected, the magnitudes of out-of-sample pricing errors jump significantly from normal to transition period, and further reach an astonishing level in the crisis period as Argentina approaches the eventual default. On average, the mean absolute pricing errors in the crisis period are about 3 to 4 times the errors in the transition period, and they are over 10 times the mean absolute pricing errors in the normal period. For example, the mean absolute pricing error for the 4-year contract is 15 basis points in the normal period, which jumps to 51 basis points in the transition period, and further reaches $190 \mathrm{bps}$ in the crisis period. The decline of pricing accuracy as measured by the median pricing errors from the normal to the transition and then to the crisis period is even more conspicuous. For example, the median pricing error for the 9 -year contract is 3 basis points in the normal period, and it is -101 basis points in the transition period, and it balloons to -314 basis points in the crisis period. Fourth, in both transition and crisis periods, the model still underprices short default swap contracts and overprice contracts with medium maturities. However, unlike in the normal period, the model seems to overprice long maturity default swap contracts in both transition and crisis periods.

Finally, for each of the three sub-periods, the model performs the worst for short maturity contracts, especially for the 1-year maturity. As discussed before, there is much more variation in default swap premiums for contracts at the short end of the maturity spectrum. This likely contributes to the large pricing errors for the 1-year contract. This phenomena is similar to situation in option pricing models, where evidences show that option pricing models usually perform the worst for short maturity contracts compared to medium and long term contracts (see Bakshi, Cao and 
Chen (1997)).

The deterioration in the pricing performance from the normal period to the transition and to the crisis periods could be due to several reasons. In the transition and crisis periods, there may be a liquidity issue in the default swap market on Argentine debt, so the quality of the default swap quotes may not be as good as those in the normal period. Though we take the completeness of our sample period as an advantage of this study, we suggest readers to interpret the pricing errors in the transition and crisis periods with caution. Second, we have kept the parameters constant in calculating out-of-sample pricing errors for all three sub-periods, which may also contribute to the differences in pricing performances from period to period. Usually the farther away a time period is from the period that the parameters are estimated, the worse the model will perform. Finally, from the normal period to the transition period, and further to the crisis period, there may be some structural changes in the market's expectation of default, and the "true" parameters of the model might have changed from period to period. All these issues are interesting and important, however, they are beyond the scope of this paper, and we will leave them as topics for future research.

\subsection{What Did the Market Expect of Argentina Default?}

Besides the in-sample and out-of-sample pricing performances of the model, one issue of particular interest to us is what the credit market expected of the Argentina default over the course of the sample period. Specifically, what were the default probabilities, under both physical and riskneutral measures, expected by the credit default swap traders during the sample period? Did the third party rating agencies lead or lag the credit market in downgrading Argentine debts? How did the third-party credit ratings assigned to Argentine debt compare to other debts with similar ratings? The rich cross-section and long time-series of our data set make it possible for us to explore answers to these questions.

Using the parameter estimates reported in Table 2, we are able to back out both the physical and risk-neutral default probabilities, as well as the expected recovery rate, from the market default swap prices. In calculating the default probabilities at time t, we keep the estimates of the parameter set fixed, while using the contemporaneous 2- and 10-year interest rate swap and the 5-year default swap prices at time t to extract the implied state variables used in the computation. Panel A of table 5 reports the statistics of the implied 1-year physical and risk-neutral default probabilities for the normal, the transition, and the crisis periods of our sample period. The calculation of the 1-year risk-neutral default probabilities are based on the following formula, $D P=E^{Q}\left[e^{-\int_{0}^{1} h(s) d s}\right]$ , where $h(s)$ is the time s instantaneous hazard rate, and the expectation is taken under the risk neutral measure $Q$ (see the Appendix for details). The 1-year physical default probabilities are obtained in a similar way.

We can make the following observations on panel A of table 5. First, in each of the three sub-periods, the 1-year risk-neutral default probabilities are always higher than the 1-year physical default probabilities, as predicted by some theoretical results in literature (see Bakshi et al. (2001b)). For example, the median 1-year physical default probability in the normal period is $4.67 \%$, while 
the median 1-year risk-neutral default probability at the same period is $5.50 \%$. While the wedge between the median physical default probabilities and the median risk-neutral default probabilities doesn't seem to change much from period to period in our study, this does not suggest that the difference between those two default probabilities should stay the same over time. Rather, the gap between these two default probabilities may very well vary over time, since it depends on the risk aversion of market participants, the magnitude of the physical default probability, the market expectation of the density of the recovery rate under physical measure conditional on default, and the relation between all the state variables which could affect the price of the underlying reference debt (see Bakshi et al. (2001b)).

Second, both the 1-year physical and and the risk-neutral default probabilities increase substantially from the normal to the transition period and from the transition to the crisis period as Argentina approached eventual default. For example, the median 1-year risk-neutral default probability is $5.50 \%$ in the normal period, while it is $11.88 \%$ in the transition period, and $32.44 \%$ in the crisis period. Consider the 1-year physical default probability, it touched low at $1.54 \%$ in the normal period, and eventually reached high around $50 \%$ at the end of the sample period.

As panel A of table 5 shows, the difference between the 1-year risk-neutral and physical default probabilities varies from period to period, so what drives variations in the difference of the two default probabilities? Bakshi et al. (2001b) shows that the difference between these two default probabilities depends on the risk aversion of market participants, the magnitude of the physical default probability, and the market expectation of the recovery rate under physical measure. Empirically, these factors may be related to the the change in business cycle, the international and domestic credit conditions, and the overall strength of the economy. To analyze causes of changes in the wedge between the two default probabilities, we run the following regression:

$$
\Delta D P(t)=\alpha_{0}+\alpha_{1} T 10(t)+\alpha_{2} \operatorname{Term}(t)+\alpha_{3} \operatorname{Credit}(t)+\alpha_{4} \operatorname{Embi}(t)+\alpha_{5} \operatorname{Merv}(t)+\epsilon(t),
$$

where $\triangle D P(t)$ is the wedge between the risk-neutral and the physical default probabilities, $\mathbf{T}-\mathbf{1 0}$ is the 10-year Treasury yield, Term is the spread between the 6-month and 10-year Treasury yields, Credit is the US credit spread between the AAA and BBB corporate Merrill Lynch bond indices, Embi is the spread between the 10-year US Treasury yield and the JP Morgan Emerging Market Bond Index for Argentina, and Merv is the BUSE Merval stock price index of Argentina.

Panel B of table 5 reports the parameter estimates and the t-statistics (in parentheses) of the regression. First, we note that the 10-year US Treasury yield is negative and significant in the regression, while at the same time, the term premium of the US term structure is positive and significant. These two results are somewhat puzzling, since both a high long term yield rate and a large term premium of the term structure point to a steep yield curve, which is usually an indication of recovery phase in the US economy, but we have opposite signs on these two variables. Second, the US credit premium is positive and insignificant, while the EMBI bond spread index for Argentina is positive with a t-statistic of 11.94. This set of results indicate that worsening in both Argentine domestic and the US credit conditions amplify the difference between the risk-neutral and physical 
default probabilities implied in Argentine sovereign debts. Third, the Argentine stock index return is negative and significant with a t-statistic value of -1.99. Taken together, the regression results suggest that the business cycle, the international and domestic credit conditions, and the overall domestic economic health are important drivers of the gap between the risk-neutral and the physical default probabilities.

Figure 2 plots the 1-year physical and risk-neutral default probabilities, as well as the default probabilities implicit in the ratings assigned to the Argentine sovereign debts by Moody's and Standard and Poor's over the entire sample period. One obvious feature of the graph is that the 1-year physical and risk-neutral default probabilities are highly correlated, where the risk-neutral default probability moves closely together with its physical counterpart. Figure 2 also confirms that the 1-year risk-neutral default probability is always higher than the physical default probability during the sample period. During most of the normal period from February 1999 to March 2001, both 1-year physical and risk-neutral default probabilities stayed below the $10 \%$ level, with lows around $2 \%$. Around March 2001, however, the 1-year physical and risk-neutral default probabilities jumped above the $10 \%$ level for good, and further reached the magnitude of $30 \%$ around July 2001 , and eventually shot over $50 \%$ at the end of the sample period.

We now turn to assess whether the credit ratings assigned to Argentine sovereign debts by major rating agencies such as Moody's and Standard and Poor's are comparable to debts with similar default likelihood, and whether the rating agencies led or lagged the market in downgrading Argentine debts. I so doing, we assume that the default likelihoods are the same between corporate and sovereign issues as long as they are assigned the same ratings from the same agency. We also assume that the corresponding ratings between Moody's and S\&P have the same default probabilities. We use actions by Moody's and S\&P on the 10-year 11 percent fixed coupon Eurobond maturing on October 9, 2006 as the benchmark. Due to lack of historical data on finer ratings in the broad rating class of Caa by Moody's (or CCC by S\&P), we only examine actions by the two rating agencies up to the time when the debt was downgraded to the broad class of Caa (or CCC).

Figure 2 shows that before October of 1999, the Moody's assigned an overly generous rating of Ba3 to the Argentine debt whose implicit default likelihood is clearly lower than the market expected default probability. ${ }^{14}$ After seven months of waiting, Moody's downgraded Argentine debt from Ba3 to B1 on 10/06/1999. Between October 1999 and October 2000, the default likelihood of Moody's rating of B1 on the Argentine debt are pretty much in line with the 1-year default probabilities implied in default swap premiums. From October 2000 to March 2001, the market expected default likelihood jumped to a higher level, however, Moody's maintained the B1 rating on the bond until 03/28/2001 when it downgraded the bond to B2, about five months after the market. Moody's then downgraded the bond from B2 to B3 on 07/13/2001, and from B3 to Caa1 on $07 / 26 / 2001$, both were behind the market reactions.

Compared to Moody's, S\&P assigned even more over-optimistic ratings on the Argentine debt.

\footnotetext{
${ }^{14}$ The 1-year default probabilities implicit in credit ratings are taken from a table in Carty (1997), which is based on data of U.S. corporate bonds from 1983 to 1996.
} 
For most of the normal period, before November 2000 to be precise, S\&P's rating on the bond is $\mathrm{BB}$, whose implicit default likelihood is $0.68 \%$, way below the market expectation of $4.67 \%$. S\&P downgraded the bond from BB to BB- on 11/14/2000, whose implicit default probability of $2.69 \%$ is still about half of what the market expected. After three months, $\mathrm{S} \& \mathrm{P}$ downgraded Argentine debt from BB- to $\mathrm{B}+$, but the implicit default likelihood of this rating is $4.04 \%$, which is less than half of the default probability implied in the CDS prices. S\&P later downgraded the bond from $\mathrm{B}+$ to B on 05/08/2001, from B to B- on 07/12/2001, and from B- to CCC+ on 10/09/2001. Figure 2 shows that, all the downgrades made by $\mathrm{S} \& \mathrm{P}$ were behind the market moves, and the credit ratings assigned to Argentine debt by S\&P were generally higher than what perceived by the market.

In sum, in the case of Argentine sovereign debt, both Moody's and S\&P seemed to have assigned over generous ratings to the Argentine debts during our sample period, and they lagged the credit market in downgrading the debt. However, compared to S\&P, Moody's did a better job in assigning ratings on Argentine debt which were closer to the market expectations.

\section{Specification Analysis}

In this section, we first examine what are the likely economic forces that drive changes in Argentine credit default swap premiums. In particular, we examine the correlation between the extracted three state variables in our model (two term structure factors and one name-specific distress factor) with a group of financial and macroeconomic variables. We next analyze the time series properties of the pricing errors of our default swap model to detect whether the pricing errors are related to any systematic factors outside the default swap model.

\subsection{Factor Specification}

In our default swap model, the two term structure of interest rate factors can be backed out from the 2- and 10-year interest rate swap rates, and the name-specific distress factor can be extracted from the 5-year credit default swap premium plus the two interest rate swap rates (Duffee (1999), Duffie and Singleton (1997), Duffie et al. (2002) and others followed similar approach). An interesting question to ask is whether those "true" underlying state variables are closely related to any observable financial and economic variables. To tackle the issue, we examine correlations between the three extracted state variables and a group of U.S. and Argentine macroeconomic and financial variables. Due to the high frequency of our default swap data, we focus on the financial variables that are available on a weekly basis, and exclude those macroeconomic series that are available only on quarterly or annual frequencies, such as the debt/GDP ratio, the foreign exchange reserves and other low frequency variables.

Table 6 displays the correlation between the three implied state variables and the following economic and financial variables: the 10-year U.S. Treasury yield, the term premium between the 6-month and the 10-year U.S. Treasury yields, the credit spread between the U.S. AAA and BBB Merrill Lynch corporate bond indices, the spread between the 10-year U.S. Treasury yield and 
the JP Morgan EMBI Index for Argentina (Embi), and the weekly return on the Argentine stock index Merval (Merv). We can make the observations that, first, the first extracted factor of the term structure of interest rates is highly negatively correlated with the term premium between the 6-month and the 10-year Treasury yields with a coefficient of -0.935. In other words, the first extracted term structure variable is highly correlated with the negative slope of the U.S. treasury term structure. Next, the second extracted term structure variable has a high correlation with the 10-year Treasury yield with a coefficient of 0.948. These findings are consistent with previous evidence in the literature on 2-factor CIR type models (see Duffie and Singleton (1997)), and Keswani (2002)), even though previous studies used solely U.S. term structure of interest rate data in their estimations, while both term structure of interest rate and Argentine default swap data are utilized in a single estimation in our study.

Third, the implied name-specific distress factor is highly correlated with the spread between the 10-year U.S. Treasury yield and the JP Morgan EMBI index with a correlation coefficient of 0.986. On the other hand, there is not much correlation between the name-specific distress factor and the weekly stock index return. In fact, the correlation between the extracted third factor and the Argentine stock index return even comes up with a wrong sign. This result seems to suggest that, in proxying the country-specific factor for sovereign bonds, stock index return for that country is probably not an ideal choice, while the spread between the country's bond index and the U.S. government bond index could be a good candidate.

Finally, some other strong correlations among the implied state variables and the selected economic variables are also note-worthy. For example, the first term structure factor is strongly and negatively correlated with the U.S. credit spread, the implied name-specific distress factor, and the Argentina EMBI spread. Also, the implied name-specific factor is strongly positively correlated with the U.S. term premium. Together, these results suggest that, at least for our sample period, when the U.S. term structure of interest rate is steep, credit conditions in both the U.S. debt market and the Argentine sovereign bond tend to worsen. This is not surprising, since the current economic downturn in the U.S. coincides with a steep U.S. yield curve and the worsening of the Argentine credit situation.

\subsection{Specification Analysis of Pricing Errors}

We turn next to an analysis of the properties of the pricing errors of our default swap model. In particular, we are concerned with whether the model biases are linked to dynamic variations in certain systematic factors outside our model. To understand the structure of the remaining pricing errors, we appeal to a regression analysis to study the association between the errors and the economic factors. Specifically, we run the following time-series OLS regression:

$$
P P E(t)=\beta_{0}+\beta_{1} T \_10(t)+\beta_{2} \operatorname{Term}(t)+\beta_{3} \operatorname{Credit}(t)+\beta_{4} \operatorname{Embi}(t)+\beta_{5} \operatorname{Merv}(t)+\varepsilon(t),
$$


for each of the 1-, 3-, and 10-year contracts. In equation (24), PPE(t) is the percentage default swap pricing errors for each of the three contracts at time t, T-10(t) is the 10-year U.S. Treasury yield at time t, $\operatorname{Term}(\mathbf{t})$ is the spread between the 6-month and the 10-year Treasury yields at time t, Credit(t) is the U.S. credit spread between the AAA and BBB Merrill Lynch corporate bond indices at time t, $\mathbf{E m b i ( t )}$ is the spread between the 10-year U.S. Treasury yield and the JP Morgan EMBI Index for Argentina at time t, and $\operatorname{Merv}(\mathbf{t})$ is the weekly return on the BUSE Merval stock price index of Argentina at time t.

Table 7 reports the time-series regression results for the 1-, 3-, and 10-year default swap contracts. Several points can be made based on this table. We can first make the observation that the effects of the economy-wide factors, such as the 10-year Treasury yield, the U.S. term premium, and the U.S. credit spread, on the short term and the long term contracts are different. For example, a rise in the 10-year treasury yield tends to increase the underpricing of the default swap model for the 1- and 3-year contracts, while a decline tends to increase the overpricing for the 10-year contract. Similar observations can be made for the U.S. term premium and credit spread. Second, the signal on the significance of the term structure factors in the regression equation is mixed. For example, the 10-year treasury yield is significant and negative for the pricing errors of the 10-year contract, while it is not significant for the 1- and 3-year contracts. On the other hand, the term premium is positively significant for the 3-year contract, negatively significant for the 10-year contract, while it is not significant for the 1-year contract.

Third, none of the two Argentine variables are significant in any of the regressions. The JP Morgan EMBI bond index spread is not close to being significant for any of the three contracts, and the same can be said of the Merval stock index return. This suggests that neither the EMBI bond index spread nor the Merval stock index return would contribute to a better pricing of the default swap on the Argentine sovereign debt. Fourth, among all the factors that are outside our model, the U.S. credit spread seems to be the most important. The credit spread is significant for all the three contracts, even though the sign of the coefficient changes to negative for the 10-year contract from positive for the 1- and 3-year contracts. This result suggests there may be a common factor affecting both the U.S. and Argentine credit conditions.

The results show that, except for the credit spread, our default swap model seems to have incorporated the necessary factors that contribute to the variation in the default swap premium. If one would like to expand the systematic factor set, the U.S. credit spread seems a top candidate, at the cost of the parsimonious-ness of the model, of course.

\section{Conclusion}

Despite the increasing importance of the credit default swaps market and repeated default events in recent years, there has been few empirical investigations in the field of credit default swaps. Even less appreciated is what does the market expect of the default prospect of an underlying reference of a default swap contract during the periods before an eventual default. In this article, 
we examine the expectations of the credit market by developing a parsimonious credit default swap model, and implement the model to a unique sample of credit default swaps on Argentine sovereign debt. Our default swap model allows flexible correlation between state variables, accommodates counterparty default risk, and makes it possible to separate the expected recovery rate from the default probability.

Our empirical investigation shows that our default swap model fits the default swap data very well, and it performs well out-of-sample in the early stages of the sample period. As expected, however, after March 2001, as the eventual default date was approaching, the out-of-sample pricing errors rose substantially, especially for the short maturity contracts. There are also some kinds of "smile" effect in the pricing of default swaps in the maturity dimension, where the model seems to systematically underprice short-maturity contracts (as well as the long-maturity contracts in the early stage of sample period) and, at the same time, overprice the median-maturity contracts.

We backed out the implied default probabilities implied in default swap prices, and found that the risk-neutral default probability was always higher than its physical counterpart. Over the course of the sample period, the implied risk-neutral and physical default probabilities swung dramatically. We found that the difference between the two default probabilities was affected by changes in the the business cycle, the U.S. and Argentine credit conditions, and the overall strength of the Argentine economy. We also found that major rating agencies had assigned over-generous ratings to the Argentine sovereign debt, and they lagged the credit market in downgrading the debt.

Correlation analysis indicates that the first economy-wide factor is closely correlated to the negative slope of the U.S. term structure of interest rate, and the second factor is highly correlated to the level of the term structure at the long end. The implied name-specific factor is found to be highly correlated with the JP Morgan EMBI bond spread index for Argentina. On the other hand, we found that, if one would like to expand the systematic factor set, the U.S. credit spread seems a top candidate. 


\section{References}

Aonuma, K. and Nakagawa, H.: 1998, Valuation of credit default swap and parameter estimation for vasicek-type hazard rate model. Working Paper, University of Tokyo.

Bakshi, G., Cao, C. and Chen, Z.: 1997, Empirical performance of alternative option pricing models, Journal of Finance LII(5), 2003-2049.

Bakshi, G. and Madan, D.: 1999, Spanning and derivative security valuation, Journal of Financial Economics 55(2), 205-238.

Bakshi, G., Madan, D. and Zhang, F. X.: 2001a, Investigating the sources of default risk: Lessons from empirically evaluating credit risk models. Working Paper, University of Maryland and Federal Reserve Board.

Bakshi, G., Madan, D. and Zhang, F. X.: 2001b, Understanding the role of recovery in default risk models: The empirical comparisons and the implied recovery rates. Working Paper, University of Maryland and Federal Reserve Board.

Carty, L.: 1997, Moody's rating migration and credit quality correlation, 1920-1996. Global Credit Research, Moody's Investors Service.

Chen, R.-R. and Scott, L.: 1993, Maximum likelihood estimation for a multifactor equilibrium model of the term structure of interest rates, Journal of Fixed Income 3, 14-31.

Chen, R.-R. and Soprazenti, B.: 2003, Pricing default-triggered credit derivatives, Journal of Financial and Quantitative Analysis . forthcoming.

Cheng, W.: 1999, A new default swap valuation formula. Working Paper, City University of Hong Kong.

Collin-Dufresne, P. and Solnik, B.: 2000, On the term structure of default premia in the swap and libor markets, Journal of Finance. forthcoming.

Cossin, D., Hricko, T., Aunon-Nerin, D. and Huang, Z.: 2002, Exploring for the determinants of credit risk in credit default transaction data: Is fixed-income markets' information sufficient to evaluate credit risk? Working Paper, University of Lausanne.

Cox, J., Ingersoll, J. and Ross, S.: 1985, A theory of the term structure of interest rates, Econometrica 53, 531-552.

Dai, Q. and Singleton, K.: 2000, Specification analysis of affine term structure models, Journal of Finance LV, 1943-1978.

Das, S. and Sundaram, R.: 2000, A direct approach to arbitrage-free pricing of credit derivatives, Management Science v(46(1)), 46-62.

Duffee, G.: 1999, Estimating the price of default risk, The Review of Financial Studies 12(1), 197226.

Duffee, G.: 2002, Term premia and interest rate forecasts in affine models, Journal of Finance 57, 405-443.

Duffie, D.: 1999a, Credit swap valuation, Financial Analyst Journal pp. 73-87. 
Duffie, D.: 1999b, First-to-default valuation. Working Paper, Stanford University.

Duffie, D., Pan, J. and Singleton, K.: 1999, Transform analysis and asset pricing for affine jumpdiffusions, Econometrica 68, 1343-1376.

Duffie, D., Pedersen, L. and Singleton, K.: 2002, Modelling credit spreads on sovereign debt: A case study of russian bonds, Journal of Finance . forthcoming.

Duffie, D. and Singleton, K.: 1997, An econometric model of the term structure of interest rate swap yields, Journal of Finance 52(4), 1287-1322.

Duffie, D. and Singleton, K.: 1999, Modeling term structures of default risky bonds, Review of Financial Studies 12(4), 687-720.

Fons, J.: 1994, Using default rates to model the term structure of credit risk, Financial Analyst Journal pp. 25-32. September-October.

Houweling, P. and Vorst, T.: 2001, An empirical comparison of default swap pricing models. Working Paper, Erasmus University of Rotterdam.

Hull, J., Predescu, M. and White, A.: 2003, The relationship between credit default swap spreads, bond yields, and credit rating announcements. Working Paper, University of Toronto.

Hull, J. and White, A.: 2000a, Valuing credit default swaps i, no counterparty default risk, The Journal of Derivatives Fall.

Hull, J. and White, A.: 2000b, Valuing credit default swaps ii, including counterparty default risk, The Journal of Derivatives Fall.

Jarrow, R. and Turnbull, S.: 1995, Pricing derivatives on financial securities subject to credit risk, Journal of Finance 50, 53-85.

Jarrow, R. and Yildirim, Y.: 2002, A simple model for valuing default swaps when both market and credit risk are correlated, Journal of Fixed Income . forthcoming.

Lando, D.: 1998, On cox processes and credit risky securities, Review of Derivatives Research 2, 99-120.

Madan, D. and Unal, H.: 1998, Pricing the risks of default, Review of Derivatives Research 2, 121160.

Mussa, M.: 2002, Argentina and the Fund: From triumph to tragedy, Vol. 67, Institute for International Economics. Policy Analysis in International Economics.

Pando, M.: 2002, Estimating the argentinean term structure: A reduced-form approach. Working Paper, UCLA.

Pearson, N. and Sun, T.: 1994, An empirical examination of cox, ingersoll, and ross model of the term structure of interest rates using the method of maximum likelihood, Journal of Finance 49, 329-359.

Sarig, O. and Warga, A.: 1989, Some empirical estimates of the risk structure of interest rates, Journal of Finance 44, 1351-1360. 
White, H.: 1982, Maximum likelihood estimation of misspecified models, Econometrica 50, 1-25.

Zhou, H.: 2001, Finite sample properties of emm, gmm, qmle and mle for a square-root interest rate diffusion model, Journal of Computational Finance 2(5), 89-122. 


\section{Appendix}

\section{Proof of Proposition 1}

(1) From (7), (11) and (13), characteristic function in (13) can be written as

$$
\Phi(t, \tau ; \phi)=e^{-\left(\alpha_{r}+\Lambda_{0}+\varphi_{0}\right) \tau+i \phi \Lambda_{0}} \Phi_{1}(t, \tau ; \phi) \times \Phi_{2}(t, \tau ; \phi) \times \Phi_{3}(t, \tau ; \phi),
$$

where

$$
\begin{aligned}
\Phi_{1}(t, \tau ; \phi) & =E_{t}^{Q}\left[e^{-\left(1+\Lambda_{x_{1}}+\varphi_{x_{1}}\right) \int_{t}^{t+\tau} X_{1}(s) d s+i \phi \Lambda_{x_{1}} X_{1}(T)}\right], \\
\Phi_{2}(t, \tau ; \phi) & =E_{t}^{Q}\left[e^{-\left(1+\Lambda_{x_{2}}+\varphi_{x_{2}}\right) \int_{t}^{t+\tau} X_{2}(s) d s+i \phi \Lambda_{x_{2}} X_{2}(T)}\right], \\
\Phi_{3}(t, \tau ; \phi) & =E_{t}^{Q}\left[e^{-\int_{t}^{t+\tau} Z(s) d s+i \phi Z(T)}\right] .
\end{aligned}
$$

Based on a result in Proposition 6.2.4 in page 130 of Lamberton and Lapeyre (1996), we have

$$
\Phi_{1}(t, \tau ; \phi)=\exp \left[\mathcal{A}_{1}(t, \tau ; \phi)-\mathcal{B}(t, \tau ; \phi) \times X_{1}(t)\right],
$$

with

$$
\begin{aligned}
\mathcal{A}_{1}(t, \tau ; \phi) & =-\frac{2 \kappa_{1} \theta_{1}}{\sigma_{1}^{2}} \log \left(\frac{\gamma_{1} \cosh \left(\frac{\gamma_{1} \tau}{2}\right)+\left(\left(\kappa_{1}+\lambda_{1}\right)-i \phi \Lambda_{x_{1}} \sigma_{1}^{2}\right) \sinh \left(\frac{\gamma_{1} \tau}{2}\right)}{\gamma_{1} \exp \left(\frac{\left(\kappa_{1}+\lambda_{1}\right) \tau}{2}\right)}\right), \\
\mathcal{B}(t, \tau ; \phi) & =\frac{-i \phi \Lambda_{x_{1}}\left[\gamma_{1} \operatorname{coth}\left(\frac{\gamma_{1} \tau}{2}\right)-\left(\kappa_{1}+\lambda_{1}\right)\right]+2\left(1+\Lambda_{x_{1}}+\varphi_{x_{1}}\right)}{\gamma_{1} \operatorname{coth}\left(\frac{\gamma_{1} \tau}{2}\right)+\left(\left(\kappa_{1}+\lambda_{1}\right)-i \phi \Lambda_{x_{1}} \sigma_{1}^{2}\right)} .
\end{aligned}
$$

where $\gamma_{1} \equiv \sqrt{\left(\kappa_{1}+\lambda_{1}\right)^{2}+2 \sigma_{1}^{2}\left(1+\Lambda_{x_{1}}+\varphi_{x_{1}}\right)}$.

Similarly,

$$
\Phi_{2}(t, \tau ; \phi)=\exp \left[\mathcal{A}_{2}(t, \tau ; \phi)-\mathcal{C}(t, \tau ; \phi) \times X_{2}(t)\right],
$$

with

$$
\begin{aligned}
\mathcal{A}_{2}(t, \tau ; \phi) & =-\frac{2 \kappa_{2} \theta_{2}}{\sigma_{2}^{2}} \log \left(\frac{\gamma_{2} \cosh \left(\frac{\gamma_{2} \tau}{2}\right)+\left(\left(\kappa_{2}+\lambda_{2}\right)-i \phi \Lambda_{x_{2}} \sigma_{2}^{2}\right) \sinh \left(\frac{\gamma_{2} \tau}{2}\right)}{\gamma_{2} \exp \left(\frac{\left(\kappa_{2}+\lambda_{2}\right) \tau}{2}\right)}\right), \\
\mathcal{C}(t, \tau ; \phi) & =\frac{-i \phi \Lambda_{x_{2}}\left[\gamma_{2} \operatorname{coth}\left(\frac{\gamma_{2} \tau}{2}\right)-\left(\kappa_{2}+\lambda_{2}\right)\right]+2\left(1+\Lambda_{x_{2}}+\varphi_{x_{2}}\right)}{\gamma_{2} \operatorname{coth}\left(\frac{\gamma_{2} \tau}{2}\right)+\left(\left(\kappa_{2}+\lambda_{2}\right)-i \phi \Lambda_{x_{2}} \sigma_{2}^{2}\right)} .
\end{aligned}
$$

where $\gamma_{2} \equiv \sqrt{\left(\kappa_{2}+\lambda_{2}\right)^{2}+2 \sigma_{2}^{2}\left(1+\Lambda_{x_{2}}+\varphi_{x_{2}}\right)}$;

$$
\Phi_{3}(t, \tau ; \phi)=\exp \left[\mathcal{A}_{3}(t, \tau ; \phi)-\mathcal{D}(t, \tau ; \phi) \times Z(t)\right],
$$

with

$$
\begin{aligned}
\mathcal{A}_{3}(t, \tau ; \phi) & =-\frac{2 \kappa_{z} \theta_{z}}{\sigma_{z}^{2}} \log \left(\frac{\gamma_{3} \cosh \left(\frac{\gamma_{3} \tau}{2}\right)+\left(\left(\kappa_{z}+\lambda_{z}\right)-i \phi \sigma_{z}^{2}\right) \sinh \left(\frac{\gamma_{3} \tau}{2}\right)}{\gamma_{3} \exp \left(\frac{\left(\kappa_{z}+\lambda_{z}\right) \tau}{2}\right)}\right), \\
\mathcal{D}(t, \tau ; \phi) & =\frac{-i \phi\left[\gamma_{3} \operatorname{coth}\left(\frac{\gamma_{3} \tau}{2}\right)-\left(\kappa_{z}+\lambda_{z}\right)\right]+2}{\gamma_{3} \operatorname{coth}\left(\frac{\gamma_{3} \tau}{2}\right)+\left(\left(\kappa_{z}+\lambda_{z}\right)-i \phi \sigma_{z}^{2}\right)} .
\end{aligned}
$$

where $\gamma_{3} \equiv \sqrt{\left(\kappa_{z}+\lambda_{z}\right)^{2}+2 \sigma_{z}^{2}}$. 
Accordingly,

$$
\mathcal{A}(t, \tau ; \phi)=\mathcal{A}_{1}(t, \tau ; \phi)+\mathcal{A}_{2}(t, \tau ; \phi)+\mathcal{A}_{3}(t, \tau ; \phi)-\left(\alpha_{r}+\Lambda_{0}+\varphi_{0}\right) \tau+i \phi \Lambda_{0} .
$$

(2) Given the characteristic function in (14), it is straight-forward to show that the credit default swap premium in (6) can be expressed as:

$$
p_{\tau}=\frac{\int_{t}^{t+\tau} y_{1}\left[\left.\frac{1}{i} \frac{\partial \Phi(t, u ; \phi)}{\partial \phi}\right|_{\phi=0}\right] d u}{\int_{t}^{t+\tau} \Phi(t, u ; \phi=0) d u}
$$

with expressions for $\Phi(t, u ; \phi=0)$, and $\left.\frac{1}{i} \frac{\partial \Phi(t, u ; \phi)}{\partial \phi}\right|_{\phi=0}$ given in the following:

$$
\Phi(t, \tau ; \phi=0)=e^{\mathcal{A}(t, \tau ; 0)-\mathcal{B}(t, \tau ; 0) X_{1}(t)-\mathcal{C}(t, \tau ; 0) X_{2}(t)-\mathcal{D}(t, \tau ; 0) Z(t)},
$$

where

$$
\begin{aligned}
\mathcal{A}(t, \tau ; 0) & =\mathcal{A}_{1}(t, \tau ; 0)+\mathcal{A}_{2}(t, \tau ; 0)+\mathcal{A}_{3}(t, \tau ; 0)-\left(\alpha_{r}+\Lambda_{0}+\varphi_{0}\right) \tau \\
\mathcal{B}(t, \tau ; 0) & =\frac{2\left(1+\Lambda_{x_{1}}+\varphi_{x_{1}}\right)}{\gamma_{1} \operatorname{coth}\left(\frac{\gamma_{1} \tau}{2}\right)+\left(\kappa_{1}+\lambda_{1}\right)} \\
\mathcal{C}(t, \tau ; 0) & =\frac{2\left(1+\Lambda_{x_{2}}+\varphi_{x_{2}}\right)}{\gamma_{2} \operatorname{coth}\left(\frac{\gamma_{2} \tau}{2}\right)+\left(\kappa_{2}+\lambda_{2}\right)} \\
\mathcal{D}(t, \tau ; 0) & =\frac{2}{\gamma_{3} \operatorname{coth}\left(\frac{\gamma_{3} \tau}{2}\right)+\left(\kappa_{z}+\lambda_{z}\right)}
\end{aligned}
$$

with

$$
\begin{gathered}
\mathcal{A}_{1}(t, \tau ; 0)=-\frac{2 \kappa_{1} \theta_{1}}{\sigma_{1}^{2}} \log \left(\frac{\gamma_{1} \cosh \left(\frac{\gamma_{1} \tau}{2}\right)+\left(\kappa_{1}+\lambda_{1}\right) \sinh \left(\frac{\gamma_{1} \tau}{2}\right)}{\gamma_{1} \exp \left(\frac{\left(\kappa_{1}+\lambda_{1}\right) \tau}{2}\right)}\right), \\
\mathcal{A}_{2}(t, \tau ; 0)=-\frac{2 \kappa_{2} \theta_{2}}{\sigma_{2}^{2}} \log \left(\frac{\gamma_{2} \cosh \left(\frac{\gamma_{2} \tau}{2}\right)+\left(\kappa_{2}+\lambda_{2}\right) \sinh \left(\frac{\gamma_{2} \tau}{2}\right)}{\gamma_{2} \exp \left(\frac{\left(\kappa_{2}+\lambda_{2}\right) \tau}{2}\right)}\right), \\
\mathcal{A}_{3}(t, \tau ; 0)=-\frac{2 \kappa_{z} \theta_{z}}{\sigma_{z}^{2}} \log \left(\frac{\gamma_{3} \cosh \left(\frac{\gamma_{3} \tau}{2}\right)+\left(\kappa_{z}+\lambda_{z}\right) \sinh \left(\frac{\gamma_{3} \tau}{2}\right)}{\gamma_{3} \exp \left(\frac{\left(\kappa_{z}+\lambda_{z}\right) \tau}{2}\right)}\right), \\
\left.\frac{1}{i} \frac{\partial \Phi(t, u ; \phi)}{\partial \phi}\right|_{\phi=0}=\Phi(t, u ; \phi=0)\left[\left.\frac{1}{i} \frac{\partial \mathcal{A}}{\partial \phi}\right|_{\phi=0}-\left.\frac{1}{i} \frac{\partial \mathcal{B}}{\partial \phi}\right|_{\phi=0} X_{1}(t)\right. \\
\left.-\left.\frac{1}{i} \frac{\partial \mathcal{C}}{\partial \phi}\right|_{\phi=0} X_{2}(t)-\left.\frac{1}{i} \frac{\partial \mathcal{D}}{\partial \phi}\right|_{\phi=0} Z(t)\right],
\end{gathered}
$$

where

$$
\begin{aligned}
\left.\frac{1}{i} \frac{\partial \mathcal{A}}{\partial \phi}\right|_{\phi=0} & =\left.\frac{1}{i} \frac{\partial \mathcal{A}_{1}}{\partial \phi}\right|_{\phi=0}+\left.\frac{1}{i} \frac{\partial \mathcal{A}_{2}}{\partial \phi}\right|_{\phi=0}+\left.\frac{1}{i} \frac{\partial \mathcal{A}_{3}}{\partial \phi}\right|_{\phi=0}+\Lambda_{0}, \text { with } \\
\left.\frac{1}{i} \frac{\partial \mathcal{A}_{1}}{\partial \phi}\right|_{\phi=0} & =\frac{2 \kappa_{1} \theta_{1} \Lambda_{x_{1}} \sinh \left(\frac{\gamma_{1} \tau}{2}\right)}{\gamma_{1} \cosh \left(\frac{\gamma_{1} \tau}{2}\right)+\left(\kappa_{1}+\lambda_{1}\right) \sinh \left(\frac{\gamma_{1} \tau}{2}\right)}, \\
\left.\frac{1}{i} \frac{\partial \mathcal{A}_{2}}{\partial \phi}\right|_{\phi=0} & =\frac{2 \kappa_{2} \theta_{2} \Lambda_{x_{2}} \sinh \left(\frac{\gamma_{2} \tau}{2}\right)}{\gamma_{2} \cosh \left(\frac{\gamma_{2} \tau}{2}\right)+\left(\kappa_{2}+\lambda_{2}\right) \sinh \left(\frac{\gamma_{2} \tau}{2}\right)}, \\
\left.\frac{1}{i} \frac{\partial \mathcal{A}_{3}}{\partial \phi}\right|_{\phi=0} & =\frac{2 \kappa_{z} \theta_{z} \sinh \left(\frac{\gamma_{3} \tau}{2}\right)}{\gamma_{3} \cosh \left(\frac{\gamma_{3} \tau}{2}\right)+\left(\kappa_{z}+\lambda_{z}\right) \sinh \left(\frac{\gamma_{3} \tau}{2}\right)},
\end{aligned}
$$


and

$$
\begin{aligned}
\left.\frac{1}{i} \frac{\partial \mathcal{B}}{\partial \phi}\right|_{\phi=0} & =\frac{-\Lambda_{x_{1}}\left[\gamma_{1}^{2} \operatorname{coth}^{2}\left(\frac{\gamma_{1} \tau}{2}\right)-\left(\kappa_{1}+\lambda_{1}\right)^{2}\right]+2 \Lambda_{x_{1}} \sigma_{1}^{2}\left(1+\Lambda_{x_{1}}+\varphi_{x_{1}}\right)}{\left[\gamma_{1} \operatorname{coth}\left(\frac{\gamma_{1} \tau}{2}\right)+\left(\kappa_{1}+\lambda_{1}\right)\right]^{2}} \\
\left.\frac{1}{i} \frac{\partial \mathcal{C}}{\partial \phi}\right|_{\phi=0} & =\frac{-\Lambda_{x_{2}}\left[\gamma_{2}^{2} \operatorname{coth}^{2}\left(\frac{\left.\gamma_{2} \tau\right)}{2}\right)-\left(\kappa_{2}+\lambda_{2}\right)^{2}\right]+2 \Lambda_{x_{2}} \sigma_{2}^{2}\left(1+\Lambda_{x_{2}}+\varphi_{x_{2}}\right)}{\left[\gamma_{2} \operatorname{coth}\left(\frac{\gamma_{2} \tau}{2}\right)+\left(\kappa_{2}+\lambda_{2}\right)\right]^{2}} \\
\left.\frac{1}{i} \frac{\partial \mathcal{D}}{\partial \phi}\right|_{\phi=0} & =\frac{-\left[\gamma_{3}^{2} \operatorname{coth}^{2}\left(\frac{\gamma_{3} \tau}{2}\right)-\left(\kappa_{z}+\lambda_{z}\right)^{2}\right]+2 \sigma_{z}^{2}}{\left[\gamma_{3} \operatorname{coth}\left(\frac{\gamma_{3} \tau}{2}\right)+\left(\kappa_{z}+\lambda_{z}\right)\right]^{2}}
\end{aligned}
$$

\section{Probabilities of Survival of Underlying Reference}

The probability of survival of the underlying reference from time $t$ to $t+\tau$, under the risk neutral measure, is

$$
\begin{aligned}
G(t, \tau) & =E_{t}^{Q}\left[e^{-\int_{t}^{t+\tau} h_{1}(s) d s}\right] \\
& =e^{\mathcal{A}_{G}(\tau)-\mathcal{B}_{G}(\tau) X_{1}(t)-\mathcal{C}_{G}(\tau) X_{2}(t)-\mathcal{D}_{G}(t, \tau ; \phi) Z(t)}
\end{aligned}
$$

with

$$
\begin{aligned}
\mathcal{A}_{G}(t, \tau)= & -\frac{2 \kappa_{1} \theta_{1}}{\sigma_{1}^{2}} \log \left(\frac{\gamma_{01} \cosh \left(\frac{\gamma_{01} \tau}{2}\right)+\left(\kappa_{1}+\lambda_{1}\right) \sinh \left(\frac{\gamma_{01} \tau}{2}\right)}{\gamma_{01} \exp \left(\frac{\left(\kappa_{1}+\lambda_{1}\right) \tau}{2}\right)}\right) \\
& -\frac{2 \kappa_{2} \theta_{2}}{\sigma_{2}^{2}} \log \left(\frac{\gamma_{02} \cosh \left(\frac{\gamma_{02} \tau}{2}\right)+\left(\kappa_{2}+\lambda_{2}\right) \sinh \left(\frac{\gamma_{02} \tau}{2}\right)}{\gamma_{02} \exp \left(\frac{\left(\kappa_{2}+\lambda_{2}\right) \tau}{2}\right)}\right) \\
& -\frac{2 \kappa_{z} \theta_{z}}{\sigma_{z}^{2}} \log \left(\frac{\gamma_{3} \cosh \left(\frac{\gamma_{3} \tau}{2}\right)+\left(\kappa_{z}+\lambda_{z}\right) \sinh \left(\frac{\gamma_{3} \tau}{2}\right)}{\gamma_{3} \exp \left(\frac{\left(\kappa_{z}+\lambda_{z}\right) \tau}{2}\right)}\right)-\Lambda_{0} \tau, \\
\mathcal{B}_{G}(t, \tau)= & \frac{2 \Lambda_{x_{1}}}{\gamma_{01} \operatorname{coth}\left(\frac{\gamma_{01} \tau}{2}\right)+\left(\kappa_{1}+\lambda_{1}\right)}, \\
\mathcal{C}_{G}(t, \tau)= & \frac{2 \Lambda_{x_{2}}}{\gamma_{02} \operatorname{coth}\left(\frac{\gamma_{02} \tau}{2}\right)+\left(\kappa_{2}+\lambda_{2}\right)}, \\
\mathcal{D}_{G}(t, \tau)= & \frac{2}{\gamma_{3} \operatorname{coth}\left(\frac{\gamma_{3} \tau}{2}\right)+\left(\kappa_{z}+\lambda_{z}\right)},
\end{aligned}
$$

with $\gamma_{01} \equiv \sqrt{\left(\kappa_{1}+\lambda_{1}\right)^{2}+2 \sigma_{1}^{2}}, \gamma_{02} \equiv \sqrt{\left(\kappa_{2}+\lambda_{2}\right)^{2}+2 \sigma_{2}^{2}}$, and $\gamma_{3} \equiv \sqrt{\left(\kappa_{z}+\lambda_{z}\right)^{2}+2 \sigma_{z}^{2}}$. The probability of survival of the underlying reference under the physical measure can be obtained likewise.

\section{The Log-likelihood Function in QML Estimation}

For $t=2, \ldots, T$, the exact non-central chi-square density of $X_{t}$ conditional on $X_{t-1}$ is,

$$
f_{X}\left(X_{t} \mid X_{t-1}\right)=\Pi_{j=1}^{2} d_{j} e^{-u_{j}-v_{j}}\left(\frac{v_{j}}{u_{j}}\right)^{\frac{1}{2} q_{j}} \times I_{q_{j}}\left(2 \sqrt{u_{j} v_{j}}\right)
$$

where $d_{j}=\frac{2 \kappa_{j}}{\sigma_{j}^{2}\left[1-e^{-\kappa_{j} \Delta t}\right]}, u_{j}=d_{j} X_{j, t-1} e^{-\kappa_{j} \Delta t}, v_{j}=d_{j} X_{j, t}$, and $q_{j}=\frac{2 \kappa_{j} \theta_{j}}{\sigma_{j}^{2}}-1 . \triangle t$ is the time interval between $\mathrm{t}$ and $(\mathrm{t}-1)$, and $I_{q}($.$) is the modified Bessel function of the first kind of order q$. The Jacobian transformation in (21) is, 


$$
\begin{aligned}
J_{t}^{S} & =\left|\begin{array}{ll}
\frac{\partial S_{t}^{2}}{\partial X_{1}} & \frac{\partial S_{t}^{2}}{\partial X_{2}} \\
\frac{\partial S_{t}^{10}}{\partial X_{1}} & \frac{\partial S_{t}^{10}}{\partial X_{1}}
\end{array}\right|^{S} \\
& =\frac{\mathcal{N}^{S}}{\left[\sum_{j=1}^{4} B\left(t, \frac{j}{2}\right)\right]^{2}\left[\sum_{j=1}^{20} B\left(t, \frac{j}{2}\right)\right]^{2}}
\end{aligned}
$$

where

$$
\begin{aligned}
\mathcal{N}^{S}= & \left\{B(t, 2) \mathcal{B}_{0}(t, 2)\left[\sum_{j=1}^{4} B\left(t, \frac{j}{2}\right)\right]+[1-B(t, 2)]\left[\sum_{j=1}^{4} B\left(t, \frac{j}{2}\right) \mathcal{B}_{0}\left(t, \frac{j}{2}\right)\right]\right\} \times \\
& \left\{B(t, 10) \mathcal{C}_{0}(t, 10)\left[\sum_{j=1}^{20} B\left(t, \frac{j}{2}\right)\right]+[1-B(t, 10)]\left[\sum_{j=1}^{20} B\left(t, \frac{j}{2}\right) \mathcal{C}_{0}\left(t, \frac{j}{2}\right)\right]\right\} \\
& -\left\{B(t, 2) \mathcal{C}_{0}(t, 2)\left[\sum_{j=1}^{4} B\left(t, \frac{j}{2}\right)\right]+[1-B(t, 2)]\left[\sum_{j=1}^{4} B\left(t, \frac{j}{2}\right) \mathcal{C}_{0}\left(t, \frac{j}{2}\right)\right]\right\} \times \\
& \left\{B(t, 10) \mathcal{B}_{0}(t, 10)\left[\sum_{j=1}^{20} B\left(t, \frac{j}{2}\right)\right]+[1-B(t, 10)]\left[\sum_{j=1}^{20} B\left(t, \frac{j}{2}\right) \mathcal{B}_{0}\left(t, \frac{j}{2}\right)\right]\right\}
\end{aligned}
$$

The log-likelihood function of the two perfectly observed interest rate swap yields from $t=2$ to $\mathrm{T}$ is the sum of the log likelihoods at each period of time,

$$
L_{S}=\sum_{t=2}^{T} \log f_{X}\left(\widehat{X}_{t} \mid \widehat{X}_{t-1}\right)-\sum_{t=2}^{T} \log \left|J_{t}^{S}\right| .
$$

Similarly, the log-likelihood function of the 3-year credit default swap yield from $\mathrm{t}=2$ to $\mathrm{T}$ is,

$$
L_{c^{5}}=\sum_{t=2}^{T} \log f_{Z}\left(\widehat{Z}_{t} \mid \widehat{Z}_{t-1}\right)-\sum_{t=2}^{T} \log \left|J_{t}^{C}\right|
$$

where $f_{Z}\left(\widehat{Z}_{t} \mid \widehat{Z}_{t-1}\right)$ is the conditional density $\widehat{Z}_{t}$ given $\widehat{Z}_{t-1}$, and $J_{t}^{C}$ is the Jacobian of variable transformation,

$$
J_{t}^{C}=\frac{\mathcal{N}^{C}}{\left[\int_{t}^{t+5} \Phi(t, u ; \phi=0) d u\right]^{2}}
$$

with

$$
\begin{aligned}
\mathcal{N}^{C=} & {\left[\int_{t}^{t+5} y_{1} \frac{\partial\left(\left.\frac{1}{i} \frac{(\partial \Phi(t, u ; \phi)}{\partial \phi}\right|_{\phi=0}\right)}{\partial Z_{t}} d u\right] \times\left[\int_{t}^{t+5} \Phi(t, u ; 0) d u\right]+} \\
& {\left[\int_{t}^{t+5} y_{1}\left(\left.\frac{1}{i} \frac{\Phi(t, u ; \phi)}{\partial \phi}\right|_{\phi=0}\right) d u\right] \times\left[\int_{t}^{t+5} \Phi(t, u ; 0) \mathcal{D}(t, u ; 0) d u\right], }
\end{aligned}
$$

and

$$
\begin{aligned}
\frac{\partial\left(\left.\frac{1}{i} \frac{(\partial \Phi(t, u ; \phi)}{\partial \phi}\right|_{\phi=0}\right)}{\partial Z_{t}}= & -\Phi(t, u ; 0) \mathcal{D}(t, u ; 0)\left[\left.\frac{1}{i} \frac{\partial \mathcal{A}}{\partial \phi}\right|_{\phi=0}-\left.\frac{1}{i} \frac{\partial \mathcal{B}}{\partial \phi}\right|_{\phi=0} X_{1}-\left.\frac{1}{i} \frac{\partial \mathcal{C}}{\partial \phi}\right|_{\phi=0} X_{2}\right. \\
& \left.-\left.\frac{1}{i} \frac{\partial \mathcal{D}}{\partial \phi}\right|_{\phi=0} Z\right]-\left.\Phi(t, u ; 0) \frac{1}{i} \frac{\partial \mathcal{D}}{\partial \phi}\right|_{\phi=0} .
\end{aligned}
$$


Above results plus the assumption that the nonzero measurement errors $\left\{\varepsilon_{t}\right\}$ of on 1-, 3-, and 10-yearare default swap contracts are serially uncorrelated, and jointly normally distributed with zero mean and variance-covariance matrix $\Omega_{\varepsilon}$, gives the log-likelihood function in the maximum likelihood estimation in (21).

To implement the quasi-maximum likelihood method, we substitute the exact transition density $f_{X}\left(X_{t} \mid X_{t-1}\right)$ in (46) with a normal density: $X(t) \mid X(t-1) \sim N\left(\mu_{t}, Q_{t}\right)$, where $\mu_{t}$ is a $2 \times 1$ vector with i-th element $\mu_{t, i}=\theta_{i}\left(1-e^{-\kappa_{i} \Delta t}\right)+e^{-\kappa_{i} \Delta t} X_{i}(t-1)$, and $Q_{t}$ is a $2 \times 2$ diagonal matrix with i-th element, $Q_{t, i}=\sigma_{i}^{2} \kappa_{i}^{-1}\left(1-e^{-\kappa_{i} \Delta t}\right)\left[\frac{\theta_{i}}{2}\left(1-e^{-\kappa_{i} \Delta t}\right)+e^{-\kappa_{i} \Delta t} X_{i}(t-1)\right]$. Similarly, $f_{Z}\left(\widehat{Z}_{t} \mid \widehat{Z}_{t-1}\right)$ is also approximated by a corresponding normal density. 


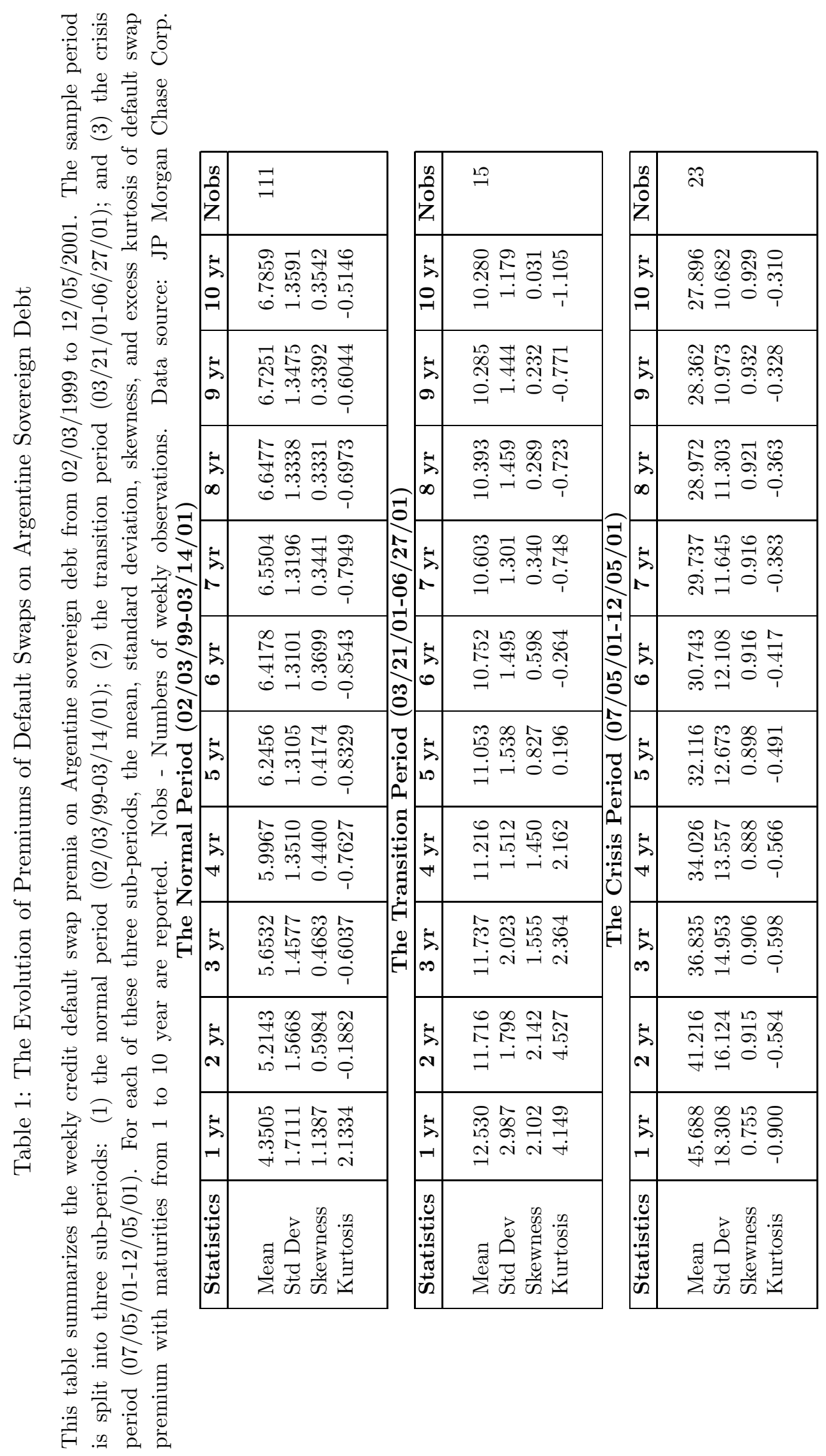




\section{Table 2: Model Parameter Estimates}

This table reports the parameter estimates of the default swap model in the quasi-maximum likelihood (QML) estimation. The estimation utilizes weekly interest rate swap and credit default swap data from 02/03/1999 to 11/01/2000. The 2- and 10-year interest rate swaps and 5-year default swap are assumed to be measured without error. The 1-, 3-, and 10-year default swaps are assumed to be measured with errors, where the errors are assumed to be normally distributed and serially uncorrelated but cross-sectionally correlated with a 3 by 3 time-invariant variance-covariance matrix satisfying Cholesky decomposition $\Sigma_{\epsilon}=C C^{\prime}$. Asymptotic standard errors based on the robust QML estimates proposed by White (1982) are reported in the parentheses. The estimated log-likelihood value is 2584.42. Data source: Federal Reserve Board and JP Morgan Chase.

\begin{tabular}{|c|c|c|c|c|c|}
\hline & \multicolumn{5}{|c|}{ Index Number (i) } \\
\hline Parameter & $\mathbf{0}$ & 1 & 2 & 3 & $\mathbf{z}$ \\
\hline$\kappa_{i}$ & & $\begin{array}{c}0.77566 \\
(0.00000)\end{array}$ & $\begin{array}{c}0.00217 \\
(0.00000)\end{array}$ & & $\begin{array}{c}0.01324 \\
(0.00052)\end{array}$ \\
\hline$\sigma_{i}$ & & $\begin{array}{c}0.01276 \\
(0.00000)\end{array}$ & $\begin{array}{c}0.02413 \\
(0.00023)\end{array}$ & & $\begin{array}{c}0.09006 \\
(0.00119)\end{array}$ \\
\hline$\theta_{i}$ & & $\begin{array}{c}0.94631 \\
(0.00000)\end{array}$ & $\begin{array}{c}0.15320 \\
(0.00004)\end{array}$ & & $\begin{array}{c}0.40229 \\
(0.00003)\end{array}$ \\
\hline$\lambda_{i}$ & & $\begin{array}{r}-0.00000 \\
(0.00335)\end{array}$ & $\begin{array}{l}-0.05996 \\
(0.01041)\end{array}$ & & $\begin{array}{c}-0.04242 \\
(0.03482)\end{array}$ \\
\hline$\Lambda_{i}$ & $\begin{array}{c}0.10674 \\
(0.02347)\end{array}$ & & & & \\
\hline$\Lambda_{x_{i}}$ & & $\begin{array}{c}-0.47687 \\
(0.00465)\end{array}$ & $\begin{array}{c}0.17266 \\
(0.00536)\end{array}$ & & \\
\hline$y_{i}$ & & $\begin{array}{c}0.72547 \\
(0.00921)\end{array}$ & & & \\
\hline$C_{1 i}$ & & $\begin{array}{c}0.00781 \\
(0.00438)\end{array}$ & 0 & 0 & \\
\hline$C_{2 i}$ & & $\begin{array}{c}0.00292 \\
(0.02891)\end{array}$ & $\begin{array}{c}0.00245 \\
(0.01193)\end{array}$ & 0 & \\
\hline$C_{3 i}$ & & 0 & $\begin{array}{c}0.00246 \\
(0.08550)\end{array}$ & $\begin{array}{c}0.00492 \\
(0.00147)\end{array}$ & \\
\hline
\end{tabular}




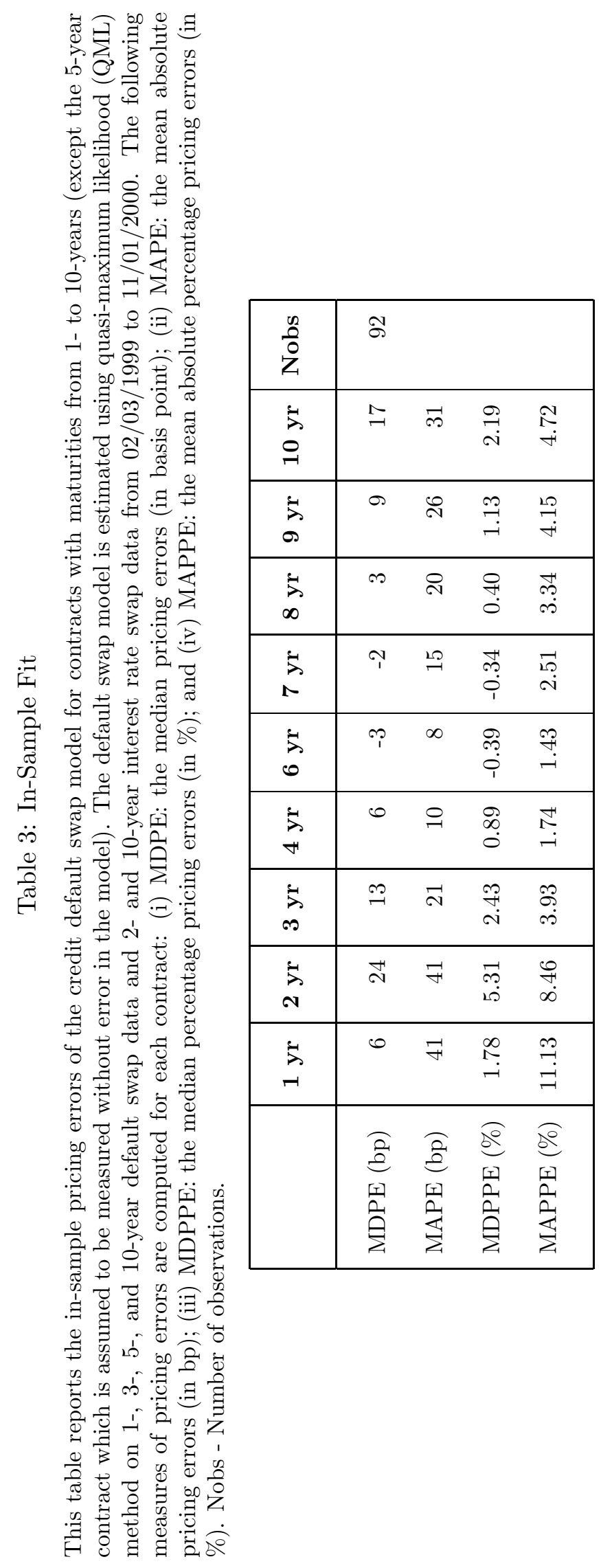


Table 4: Out-Of-Sample Pricing Errors

This table presents the out-of-sample pricing errors of the default swap model for contracts with maturities from 1- to 10-years (except 5-year contract which is assumed to be measured without error in the model). The default swap model is estimated using 1-, 3-, 5-, 10-year default swap data and 2- and 10-year interest rate swap data over the period 02/03/1999-11/01/2000. The out-of-sample pricing errors for three sub-periods are reported: (i) 11/08/2000-03/14/2001 (the normal period); (ii) 03/21/2001-06/27/2001 (the transition period); and (iii) 07/05/2001-12/05/2001 (the crisis period). The following measures of pricing error are computed for each contract: (i) MDPE: the median pricing error (in basis point); (ii) MAPE: the mean absolute pricing error (in bp); (iii) MDPPE: the median percentage pricing error (in \%); and (iv) MAPPE: the mean absolute percentage pricing error (in \%).

The Normal Period (11/08/00-03/14/01)

\begin{tabular}{|c|c|c|c|c|c|c|c|c|c|c|}
\hline Errors & $1 \mathrm{yr}$ & $2 \mathrm{yr}$ & $3 \mathrm{yr}$ & $4 \mathrm{yr}$ & $6 \mathrm{yr}$ & $7 \mathrm{yr}$ & $8 \mathrm{yr}$ & $9 \mathrm{yr}$ & $10 \mathrm{yr}$ & Nobs \\
\hline MDPE (bp) & 77 & 53 & 34 & 11 & -5 & -6 & -4 & 3 & 10 & 19 \\
\hline MAPE (bp) & 120 & 73 & 41 & 15 & 10 & 17 & 20 & 23 & 26 & \\
\hline MDPPE (\%) & 14.61 & 8.91 & 5.00 & 1.60 & -0.64 & -0.72 & -0.56 & 0.36 & 1.49 & \\
\hline MAPPE (\%) & 16.80 & 10.11 & 5.56 & 2.01 & 1.35 & 2.22 & 2.65 & 2.97 & 3.49 & \\
\hline \multicolumn{11}{|c|}{ The Transition Period $(03 / 21 / 01-06 / 27 / 01)$} \\
\hline Errors & $1 \mathrm{yr}$ & $2 \mathrm{yr}$ & $3 \mathrm{yr}$ & $4 \mathrm{yr}$ & $6 \mathrm{yr}$ & $7 \mathrm{yr}$ & $8 \mathrm{yr}$ & $9 \mathrm{yr}$ & $10 \mathrm{yr}$ & Nobs \\
\hline MDPE (bp) & 276 & 163 & 121 & 44 & -46 & -58 & -96 & -101 & -83 & 15 \\
\hline MAPE & 316 & 184 & 126 & 51 & 45 & 69 & 93 & 104 & 102 & \\
\hline MDPPE (\%) & 24.55 & 14.59 & 10.91 & 4.10 & -3.99 & -6.05 & -8.52 & -10.00 & -8.95 & \\
\hline MAPPE (\%) & 24.77 & 15.73 & 10.66 & 4.66 & 4.32 & 6.48 & 9.26 & 10.43 & 9.91 & \\
\hline \multicolumn{11}{|c|}{ The Crisis Period $(07 / 05 / 01-12 / 05 / 01)$} \\
\hline Errors & $1 \mathrm{yr}$ & $2 \mathrm{yr}$ & $3 \mathrm{yr}$ & $4 \mathrm{yr}$ & $6 \mathrm{yr}$ & $7 \mathrm{yr}$ & $8 \mathrm{yr}$ & $9 \mathrm{yr}$ & $10 \mathrm{yr}$ & Nobs \\
\hline MDPE (bp) & 1199 & 780 & 375 & 156 & -122 & -207 & -270 & -314 & -345 & 23 \\
\hline MAPE (bp) & 1370 & 909 & 470 & 190 & 134 & 230 & 301 & 357 & 398 & \\
\hline MDPPE (\%) & 33.02 & 25.37 & 13.42 & 5.77 & -4.56 & -7.89 & -11.01 & -12.98 & -14.20 & \\
\hline MAPPE (\%) & 32.06 & 23.85 & 13.45 & 5.85 & 4.61 & 8.12 & 10.86 & 13.01 & 14.64 & \\
\hline
\end{tabular}




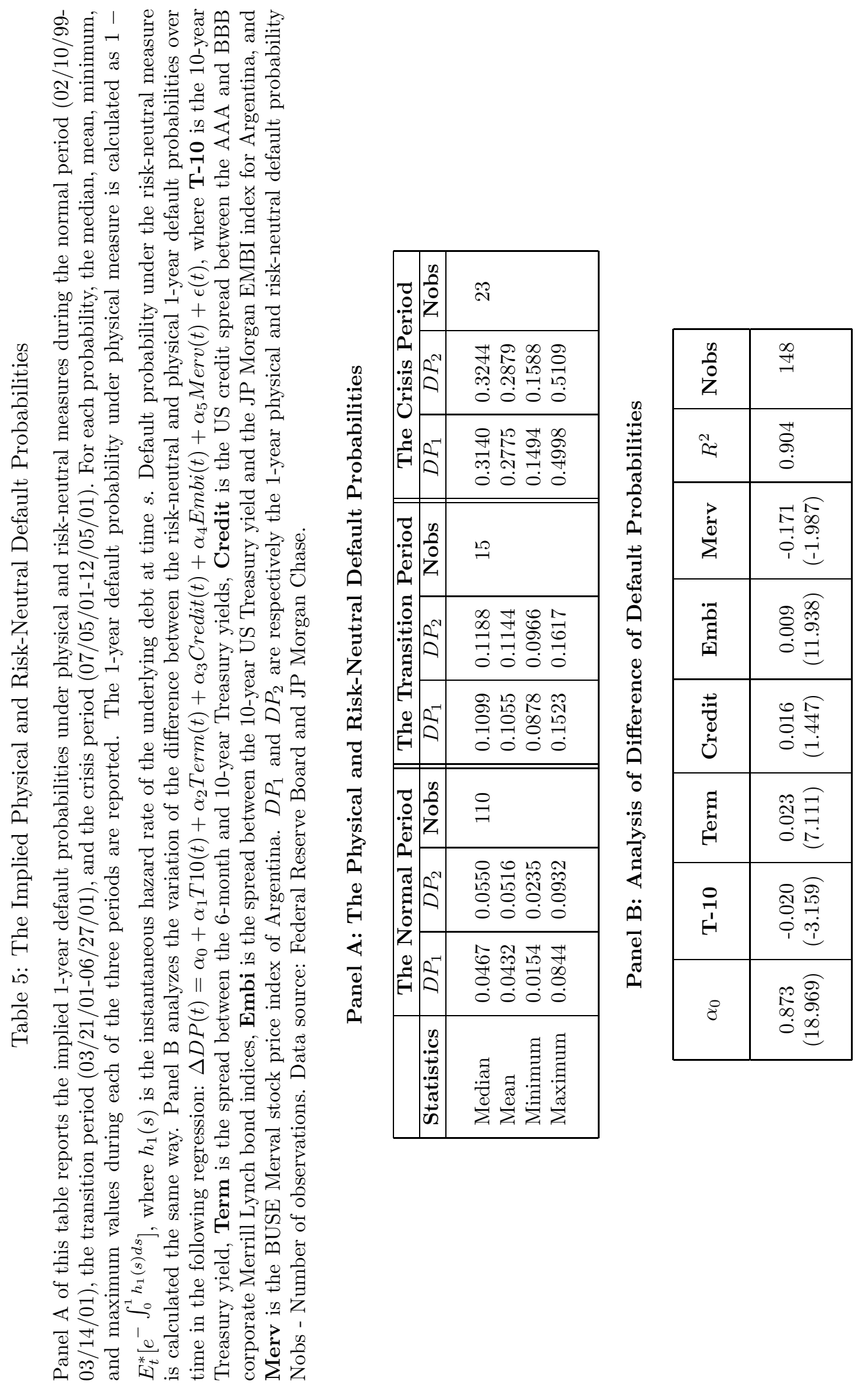




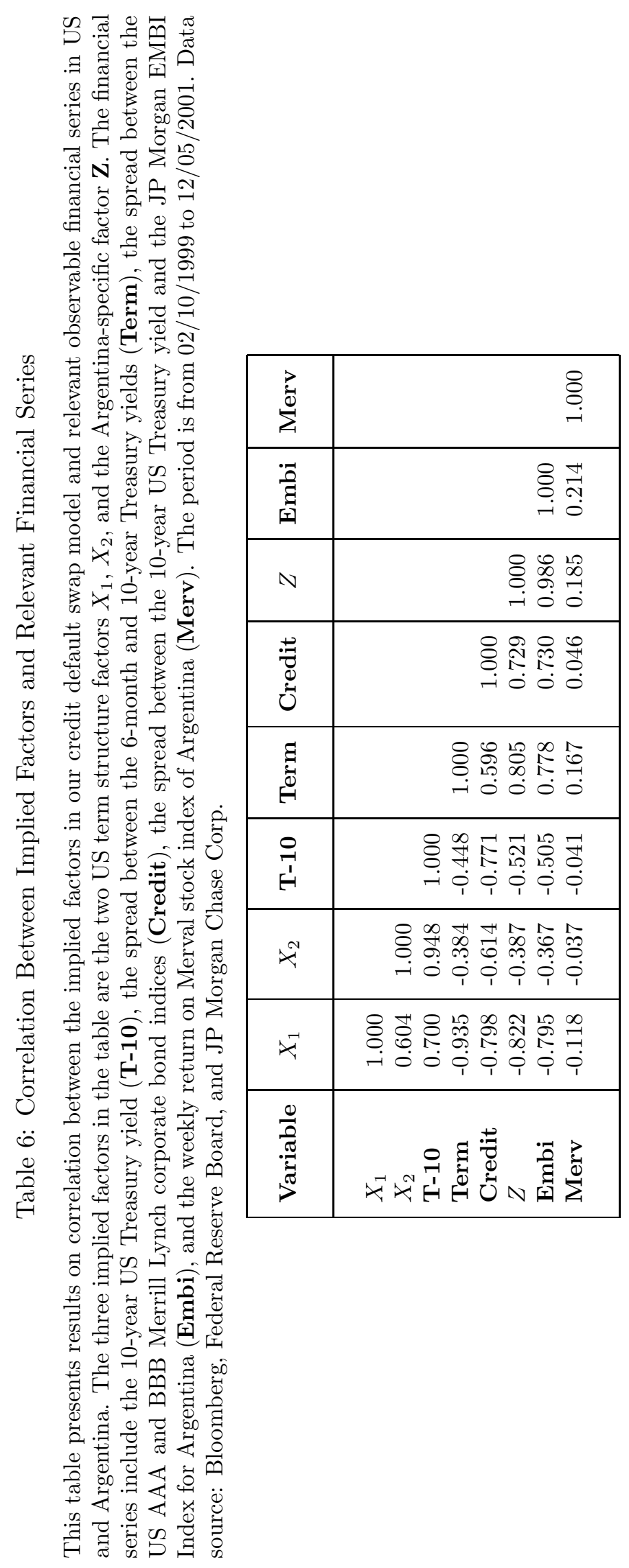




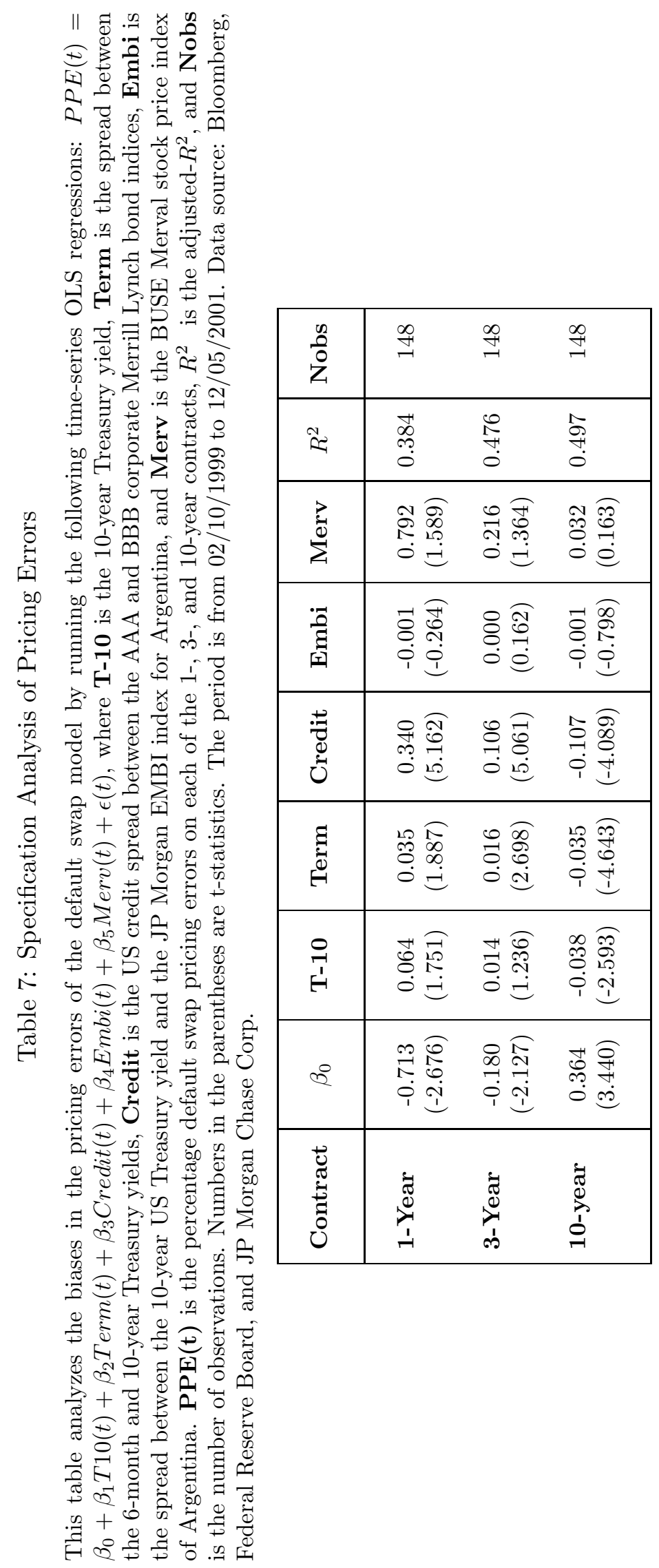


Figure 1: Premiums of Default Swaps on Argentine Sovereign Debt (02/03/1999 - 12/05/2001)

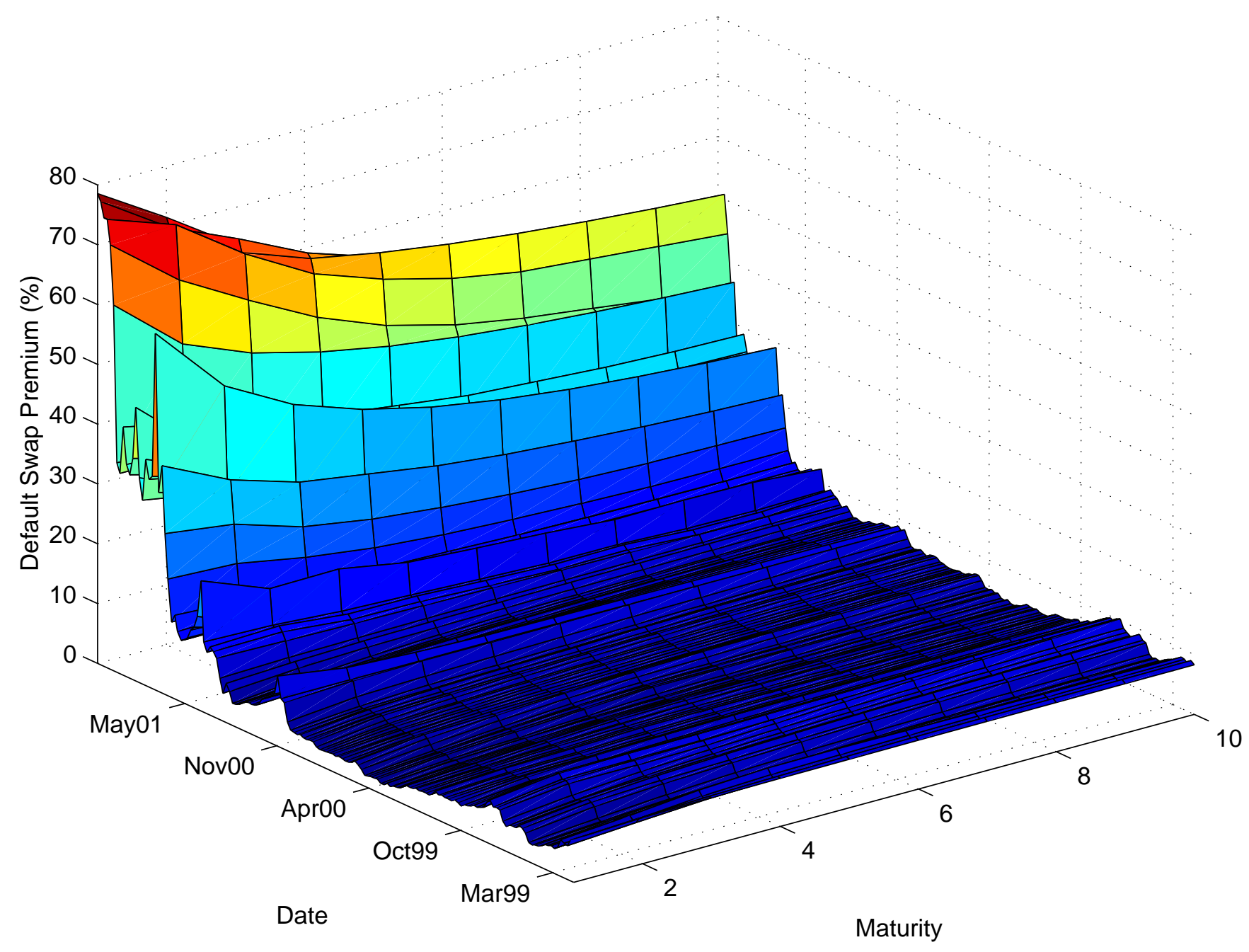


Figure 2: 1-Year Physical and Risk-Neutral Default Probabilities of Argentine Sovereign Debt

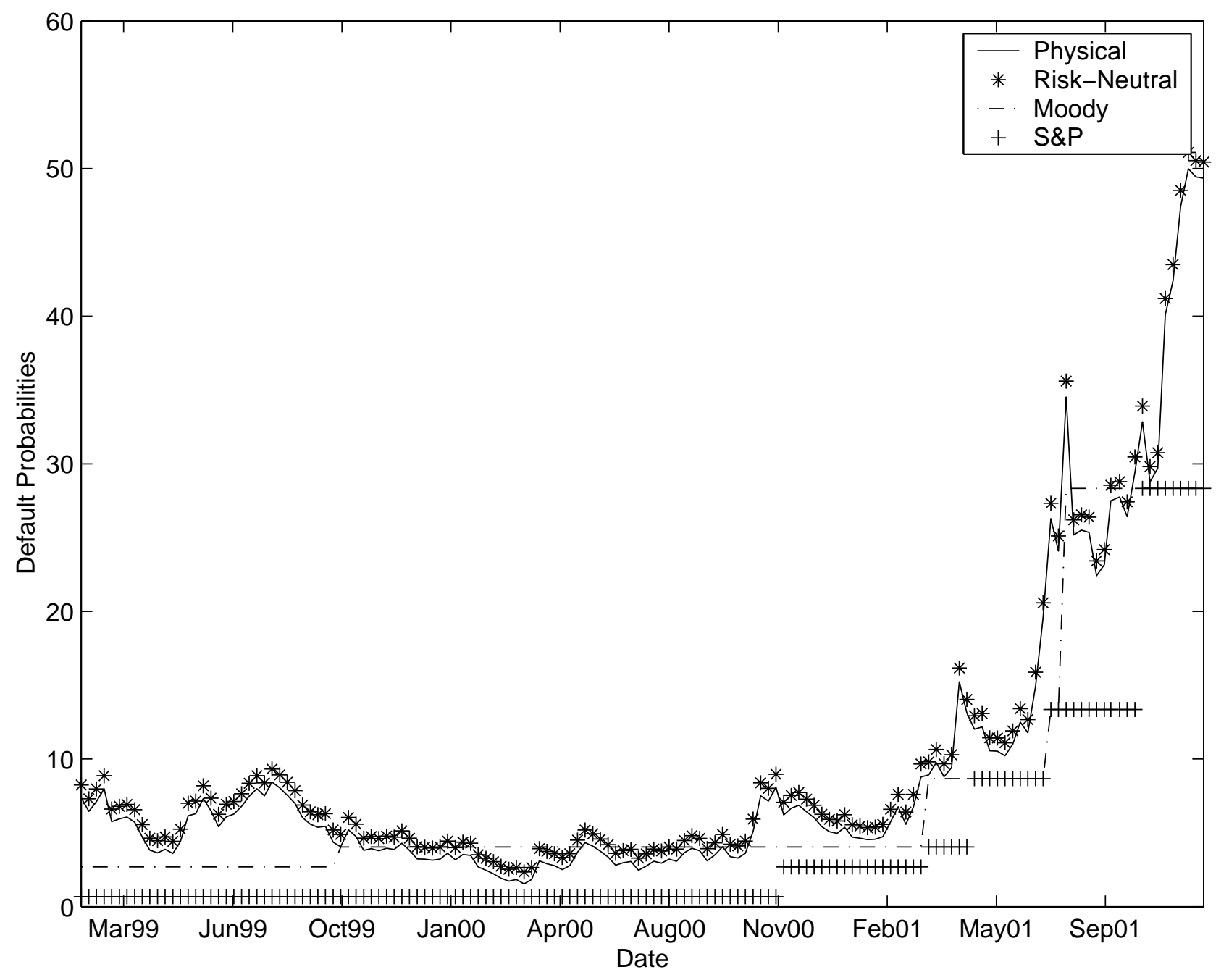

